\author{
Economics Working Paper Series
}

\author{
2015/018
}

\title{
Fiscal Policy Effects in a Heterogeneous-Agent OLG Economy with an Aging Population \\ Shinichi Nishiyama
}

The Department of Economics

Lancaster University Management School

Lancaster LA1 4YX

UK

(C) Authors

All rights reserved. Short sections of text, not to exceed two paragraphs, may be quoted without explicit permission, provided that full acknowledgement is given. 


\title{
Fiscal Policy Effects in a Heterogeneous-Agent OLG Economy with an Aging Population*
}

\author{
Shinichi Nishiyama ${ }^{\dagger}$ \\ Lancaster University
}

August 14, 2015

\begin{abstract}
This paper incorporates the aging population projected by the U.S. Social Security Administration to a heterogeneous-agent OLG model with idiosyncratic wage shocks and analyzes its effects on individual households, the government budget, and the overall economy. The fiscal gap caused by the demographic change is $2.94 \%$ of GDP under the intermediate projection. The effect of the aging population is large by itself and depends significantly on how the government finances the cost of the demographic change. There is a strong trade-off between efficiency and equity, and this paper quantitatively assesses the pros and cons of stylized fiscal reform plans.
\end{abstract}

JEL Classification Numbers: D91, E62, H31.

Keywords: dynamic general equilibrium; heterogeneous agents; overlapping generations; aging population; fiscal policy.

\footnotetext{
*For providing and explaining the data used in this paper, I am grateful to Alice Wade, Michael Morris (both Social Security Administration), John Sabelhaus, Kevin Moore (both Federal Reserve Board), Patricia Neuman, Juliette Cubanski (both Kaiser Family Foundation), and Anthony Damico (independent consultant). For their helpful comments and suggestions on the earlier version of this paper, I also thank Ayşe İmrohoroğlu, Florian Scheuer, numerous economists at the Congressional Budget Office, and the seminar/conference participants at the Michigan Retirement Research Center, George Washington University, Congressional Budget Office, National Graduate Institute for Policy Studies, Econometric Society North American Summer Meeting, and Kansai University. I am responsible for any remaining errors.

${ }^{\dagger}$ Department of Economics, Lancaster University Management School, Lancaster, LA1 4YX, United Kingdom. E-mail: s.nishiyama@lancaster.ac.uk.
} 


\section{Introduction}

The current fiscal policy in the United States is not sustainable. This is primarily because of the ongoing demographic changes, such as retiring baby boom generations, declining mortality rates, and stable but relatively low fertility rates. This aging population will reduce the share of the working-age population and increase the share of the retired population in the future; thus it will likely decrease labor supply per capita and output per capita relative to the economy without the aging population. The aging population will also reduce the government's tax revenue per capita, as the government relies more on taxes on labor income, and will increase the government's transfer spending per capita, as elderly households are the main recipients of Social Security benefits. Therefore, the aging population will create a sizable fiscal gap in the government's fiscal policy, and the government will eventually have to cut its transfer spending or raise tax rates or both. These additional fiscal policy changes aimed to close the fiscal gap will likely exacerbate the negative effect of the aging population in the economy.

This paper extends a heterogeneous-agent overlapping-generations (OLG) model with uninsurable wage and mortality shocks by incorporating an aging population projected by the U.S. Social Security Administration (SSA) and analyzes the general-equilibrium effect of the aging population on the behavior and welfare of individual households, the government's budget, and the aggregate economy. The households are heterogeneous with respect to their age, working ability (hourly wage), wealth, and the average historical earnings that will determine their future Social Security benefits. Each year, households receive idiosyncratic wage shocks and determine their consumption, working hours, and saving to maximize their lifetime utility, taking factor prices, the government policy schedule, and the population projection as given. The government fiscal policies, such as the income taxes and the Social Security programs, involve both inter-generational and intra-generational redistribution and risk sharing. Therefore, this setting is critically important to analyze the effect of the aging population on the overall economy and the government budget as well as the effect of the future fiscal policy changes on individual household's behaviors and wellbeing.

This paper then calibrates the model to the 2014 U.S. economy. One of the difficulties in incorporating the aging population to a heterogeneous-agent OLG model is, however, the population distribution in the current year (2014 in this paper) is not stationary, thus, the model cannot describe the baseline economy as a stationary equilibrium. For that reason, this paper calibrates the model to the 2014 U.S. economy by solving it for an equilibrium transition path between 1975 and 2200. As discussed in the above, the aging population creates the government's budget deficits in the future and surpluses in the past under the currentlaw policy. In the aging-population baseline economy, this paper assumes that the government decreases 
or increases its consumption spending so that the debt per capita stays at the same level after productivitygrowth adjustment $]^{1}$

This paper finally conducts a set of policy experiments that replace the government's financing assumption to close the fiscal gap generated by the aging population. Although most of the fiscal imbalances are generated by the Social Security program, especially its old age and survivors insurance (OASI) program and hospital insurance (HI) program, there is no reason for the government to close the fiscal gap within the Social Security system. Therefore, this paper introduces a broad range of stylized fiscal policy changesthose in the uniform lump-sum taxes, the progressive income tax rates, the flat consumption tax rate-in addition to the changes in Social Security benefit schedules and payroll tax rates. The paper addresses how the behavior and well-being of individual households and the overall economy will differ under these financing assumptions of the cost of the aging population. Not surprisingly, there are a trade-off between efficiency (e.g., GDP growth) and equity (e.g., social welfare) and a trade-off between the well-beings of the current households and the future households; and this paper quantitatively assesses the pros and cons of each alternative fiscal policy.

The main findings of this paper are as follows: First of all, the macroeconomic and budgetary effects of the aging population are large by itself. In the aging-population baseline economy, where the feedback effect of future fiscal policy changes are turned off, under SSA's population projection Alternative 2 (intermediate scenario), the projected demographic changes will decrease GDP per capita by 5.4\% in 2039 and $7.2 \%$ in the long run, primarily because the share of the working-age households in the economy declines over time. To balance the budget, the government will have to cut its primary deficits as a share of GDP by 3.6 percentage points in 2039 and by 5.5 percentage points in the long run. The fiscal gap in the current-law fiscal policy, measured by the present discount sum of the current and future primary deficits, is $2.94 \%$ as a percentage of the present discount sum of the current and future GDP under this intermediate population projection. In other words, the government will have to reduce its primary deficits by $2.94 \%$ of GDP each year starting in 2014 in order to make its current fiscal policy (programs) sustainable.

If the government tries to close this fiscal gap, more realistically, by increasing taxes or cutting transfer spending or both, the effect of the demographic changes with the additional fiscal policy change will differ significantly, depending on how the government finances the budgetary cost of the aging population. For example, GDP per capita will decrease by $10.0 \%$ in 2039 and $25.8 \%$ in the long run, relative to the economy

\footnotetext{
${ }^{1}$ In the model economy of this paper, the government's consumption is not in the household's utility function. Thus, by assumption, its change does not affect the household's behavior and wellbeing. The current-law fiscal policy is not sustainable, but it is uncertain when and how the government will change its policy to make it sustainable. To construct an aging-population baseline economy, therefore, this paper adjusts the government consumption to turn off any behavioral feedback from future policy changes.
} 
without the aging population, if the government increases marginal income tax rates proportionally; but GDP per capita will increase modestly by $1.7 \%$ in 2039 and $3.1 \%$ in the long run if the government instead decreases Social Security benefits proportionally. Cutting Social Security benefits looks better than raising marginal income tax rates in terms of its effects on output. However, the welfare results indicate that households in the current generation - those aged 21 and older at the time of the policy change-strongly prefer increasing marginal income tax rates to cutting Social Security benefits, at the expense of households in the future. If the government cares about the level of future output and the inter-generational equity at the same time, it is probably safe to consider one of the following options: (1) raising the flat consumption tax to balance the budget each year, and (2) cutting Social Security benefits and raising payroll tax rates proportionally roughly on 50-50 basis instead. As the fiscal gap generated by the demographic changes increases over time, delaying the policy reform (by increasing the government debt) is not desirable in terms of both the economic output and the intergenerational equity.

Needless to say, this is not the first paper that incorporates the U.S. aging population into a generalequilibrium OLG model and analyzes its macroeconomic and welfare effects. Relative to the previous literature, however, the present paper has a variety of strengths in the model economy and calibration procedure.

To the best of my knowlege, Auerbach and Kotlikoff (1987) are the first to incorporate the historical and predicted changes in the fertility rate to a large-scale deterministic general-equilibrium OLG model. Kotlikoff, Smetters, and Walliser (2007) incorporate the U.S. demographic changes to their 12-incomelevel deterministic general-equilibrium OLG model. Ludwig, Schelkle, and Vogel (2012) also incorporate the U.S. demographic changes to their deterministic general-equilibrium OLG model with human capital accumulation. The present paper conducts the similar exercises in a heterogeneous-agent OLG economy with idiosyncratic wage shocks and mortality shocks, so that the model can capture not only the intergenerational redistribution effect of the government fiscal policy but also its intra-generational redistribution and risk-sharing effects $2^{2}$ De Nardi, İmrohoroğlu, and Sargent (1999) incorporate the SSA's population projection to their stochastic general-equilibrium OLG model with idiosyncratic preference and endowment shocks. Yet, they use linear-quadratic approximation around the certainty-equivalent equilibrium to deal with idiosyncratic shocks. Therefore, their paper does not fully consider precautionary motives for saving and labor supply $\left.\right|^{3}$

\footnotetext{
${ }^{2}$ The previous literature that uses this class of models, without the aging population, includes İmrohoroğlu, İmrohoroğlu, and Joines (1995), Huggett (1996), Nishiyama and Smetters (2007), and Conesa, Kitao, and Krueger (2009).

${ }^{3}$ There are several other papers that analyze the effects of the demographic changes of countries or regions outside the United States. For example, Rios-Rull (2001) incorporates the Spanish population distribution to his stochastic general-equilibrium OLG model with aggregate fertility shocks. Attanasio, Kitao, and Violante (2006, 2007) construct a two-region large-open economy
} 
Most recently, Kitao (2014) incorporates the demographic change based on Census Bureau's population projection into her heterogeneous-agent OLG model with idiosyncratic wage and mortality shocks, which is similar to the one in the present paper. Kitao first calibrates the model to the 2010 stationary economy with the stationary population distribution, then she changes the conditional survival rate by age and the population growth rate of newborn households to analyze the aging population. However, her 2010 stationary benchmark economy fails to capture the current population distribution with a large group of babyboomers, thus, the model cannot accurately predict the macroeconomic effect and budgetary cost of the aging population in the short run 4 The present paper instead incorporates SSA's population projection as well as historical population directly and calibrates the model to the 2014 benchmark economy by solving the model for an equilibrium transition path between 1975 and 2200.

The rest of the paper is organized as follows: Section 2 describes the heterogeneous-agent OLG model with the projected aging population; Section 3 explains the calibration of the model to the 2014 benchmark economy; Section 4 shows the and the aging-population baseline economies; Section 5 explains the policy experiments that replace the future government policies to close the fiscal gap; and Section 6 concludes the paper.

\section{The Model Economy}

The model economy consists of a large number of overlapping-generations households, a perfectly competitive representative firm with constant-returns-to-scale technology, and a government that can credibly commit to a fiscal policy. The time is discrete, and one model period is a year, which is denoted by $t$. In a long-run stationary equilibrium, the economy is assumed to be on a balanced-growth path with a constant labor-augmenting productivity growth rate, $\mu$, and a constant (long-run) population growth rate, $\nu$. In the following model description, individual variables other than working hours are growth-adjusted by $(1+\mu)^{-t}$, and aggregate variables are adjusted by $[(1+\mu)(1+\nu)]^{-t}$.

general-equilibrium OLG model and incorporate the United Nations global population projections to it. Krueger and Ludwig (2007) construct a three-region large-open economy general-equilibrium OLG model and incorporate the United Nations population projections, too. Chen, İmrohoroğlu, and İmrohoroğlu (2007) incorporate the Japanese population distribution to their deterministic general-equilibrium OLG model. Braun, Ikeda, and Joines (2009) also incorporate the Japanese population projection to their deterministic general-equilibrium OLG model.

${ }^{4}$ See, for example, Figure 13 in Kitao (2014) and Figure 8 in the present paper. Labor supply is higher with the demographic shift during the first 30 years (2010-2040), relative to the benchmark economy, in Kitao (2014), whereas labor supply is $8.1 \%$ lower by 2039 under SSA's intermediate projection in the present paper. The relatively quick decline in labor supply in the latter is mainly predicted by the retirement of the baby-boom generation. 


\subsection{The Households}

Households in the model economy are heterogeneous with respect to their age, $i=21, \ldots, I$, beginningof-year wealth (net worth), $a \in A=\left[a_{\min }, \infty\right)$, average historical earnings used to calculate Social Security Old-Age and Survivors Insurance (OASI) benefits, $b \in B=\left[0, b_{\max }\right]$, and labor productivity, $e \in E=$ $[0, \infty)$. The households enter the economy and start working at age $i=21$, and they can live at most to age $I=120$. In each year, $t$, the households receive idiosyncratic and age-dependent working ability shocks, $e$, and they each choose their consumption, $c$, working hours, $h$, and thus wealth at the beginning of the next year, $a^{\prime}$, to maximize their expected (remaining) lifetime utility.

The households are, for simplicity, assumed to start receiving OASI benefits at their own full retirement age (FRA), $i=I_{\tilde{R}}$, which is between ages 65 and 67, depending on their birth year, although they can continue working after their FRA if they find it optimal 5 The average historical earnings, $b$, are used to approximate the average indexed monthly earnings (AIME) and determine OASI benefits. The individual working ability, $e$, follows a first-order Markov process.

\subsubsection{The State Variables}

Let $\mathbf{s}$ and $\mathbf{S}_{t}$ denote the individual state of the household and the aggregate state of the economy in year $t$, respectively,

$$
\mathbf{s}=(i, a, b, e), \quad \mathbf{S}_{t}=\left(X_{t}(\mathbf{s}), w_{G, t}\right),
$$

where $X_{t}(\mathbf{s})$ is the cumulative distribution function of households, and $w_{G, t}$ is the government's net worth per household, both at the beginning of year $t$. Let $p_{i, t}$ be the (long-run) growth-adjusted population of age- $i$ households in year $t$. The distribution function, $X_{t}(\mathbf{s})$, satisfies

$$
\int_{A \times B \times E} d X_{t}(i, a, b, e)=p_{i, t}
$$

Let $\Psi_{t}$ be the government's policy schedule as of the beginning of year $t$,

$$
\mathbf{\Psi}_{t}=\left\{c_{G, s}, \operatorname{tr}_{L S, s}, \tau_{I, s}(\cdot), \tau_{P, s}(\cdot), \operatorname{tr}_{S S, s}(\cdot), \tau_{C, s}, w_{G, s+1}\right\}_{s=t}^{\infty}
$$

where $c_{G, t}$ is the government's consumption per household, $t r_{L S, t}$ is a lump-sum transfer per household,

\footnotetext{
${ }^{5}$ Social Security OASI benefits are partially taxable when the sum of adjusted gross income and 50 percent of benefits is above $\$ 25,000$ (single) or $\$ 32,000$ (married filing jointly). Thus, it is optimal for the workers to delay the Social Security benefit claim until they are fully retired. For simplicity, this possibility is excluded in the model economy.
} 
$\tau_{I, t}(\cdot)$ is a progressive income tax function, $\tau_{P, t}(\cdot)$ is a Social Security Old-Age, Survivors, Disability, and Hospital Insurance (OASDHI) payroll tax function, $\operatorname{tr}_{S S, t}(\cdot)$ is an OASDHI benefit function, and $\tau_{C, t}$ is a flat consumption tax rate ${ }^{6}$ The government's consumption is not assumed to be in the household's utility function and thus does not affect the household's decision on private consumption and labor supply, while lump-sum transfers directly affect the household's decision through the intertemporal budget constraint. The flat consumption tax, $\tau_{C, t}$, is assumed to approximate other federal revenues, such as those from excise taxes and customs duties.

Finally, let $\boldsymbol{\Phi}_{t}$ be the population projection as of the beginning of year $t$,

$$
\boldsymbol{\Phi}_{t}=\left\{\left(p_{i, s}\right)_{i=0}^{I},\left(\phi_{i, s}\right)_{i=0}^{I}\right\}_{s=t}^{\infty}
$$

where $\phi_{i, t}$ is the conditional survival rate at the end of age $i$ in year $t$, given that the household is alive at the beginning of age $i$ in year $t$. For simplicity, the population distribution and the corresponding mortality rates are assumed to be deterministic, and households have perfect foresight about the future population distribution 7

The population projection, $\boldsymbol{\Phi}_{t}$, affects the model economy in the following ways: First, the projection of the household's own survival rates and corresponding longevity have an influence on the household's consumption, working, and saving decisions through their retirement planning. Second, projected changes in the population distribution by age (especially, the share of the working-age population) directly affect macroeconomic variables, factor prices, and the government's budget and fiscal policies. Finally, these changes in future factor prices and the government's fiscal policies generate additional effects on the household's optimal decisions—-both the current decision and future decisions — in a dynamic general-equilibrium economy.

\footnotetext{
${ }^{6}$ In this paper, the population growth rate changes over time, and the growth rates also depend on the population projection. For a better comparison of alternative fiscal policies over time as well as under different population assumptions, the current-law fiscal policy in this paper is assumed to keep the government's net worth per household, $w_{G, t}$, and consumption per household, $c_{G, t}$, at the same levels after the productivity growth adjustment, rather than to keep the government's aggregate net worth and aggregate consumption unchanged.

${ }^{7}$ Introducing aggregate uncertainty, such as total factor productivity shocks and mortality/fertility shocks, to a heterogeneousagent model causes the "curse of dimensionality" problem. When there are aggregate shocks, under the rational expectation assumption, we need to solve the household's optimization problem for all possible paths (sample paths) of the aggregate economy, which is computationally infeasible in a heterogeneous-agent economy.
} 


\subsubsection{The Optimization Problem}

Let $v\left(\mathbf{s}, \mathbf{S}_{t} ; \mathbf{\Psi}_{t}, \boldsymbol{\Phi}_{t}\right)$ be the value function of a household at the beginning of year $t$. Then, the household's optimization problem is

(1) $v\left(\mathbf{s}, \mathbf{S}_{t} ; \mathbf{\Psi}_{t}, \mathbf{\Phi}_{t}\right)=\max _{c, h, a^{\prime}}\left\{u(c, h)+\tilde{\beta} \phi_{i, t} E\left[v\left(\mathbf{s}^{\prime}, \mathbf{S}_{t+1} ; \mathbf{\Psi}_{t+1}, \mathbf{\Phi}_{t+1}\right) \mid \mathbf{s}\right]\right\}$

subject to the constraints for the decision variables,

(2) $\quad c>0, \quad 0 \leq h<1, \quad a^{\prime} \geq a_{\min }^{\prime}(\mathbf{s})$,

and the law of motion of the individual state,

(3) $\mathbf{s}^{\prime}=\left(i+1, a^{\prime}, b^{\prime}, e^{\prime}\right)$,

(4) $\quad a^{\prime}=\frac{1}{1+\mu}\left[\left(1+r_{t}\right) a+w_{t} e h+\operatorname{tr}_{S S, t}(i, b)+\operatorname{tr}_{L S, t}+q_{t}(i)-\tau_{I, t}\left(w_{t} e h, r_{t} a, \operatorname{tr}_{S S, t}(i, b)\right)\right.$

$$
\left.-\tau_{P, t}\left(w_{t} e h\right)-\left(1+\tau_{C, t}\right) c\right],
$$

$$
b^{\prime}=\mathbf{1}_{\left\{i<I_{R}\right\}} \frac{1}{i-20}\left[(i-21) b \frac{w_{t}}{w_{t-1}}+\min \left(\eta w_{t} e h, \vartheta_{\max }\right)\right]+\mathbf{1}_{\left\{i \geq I_{R}\right\}} b,
$$

where $u(\cdot)$ is a period utility function, a combination of Cobb-Douglas and constant relative risk aversion (CRRA),

(6) $u(c, h)=\frac{\left[c^{\alpha}(1-h)^{1-\alpha}\right]^{1-\gamma}}{1-\gamma}$,

$\tilde{\beta}$ is a growth-adjusted discount factor explained below, and $E[\cdot \mid \mathbf{s}]$ denotes the conditional expected value given the household's current state. The household's decision variables are constrained: consumption, $c$, is strictly positive; working hours, $h$, are nonnegative and are less than a time endowment (unity); and wealth at the beginning of the next year, $a^{\prime}$, satisfies a borrowing constraint, $a^{\prime} \geq a_{\min }^{\prime}(\mathbf{s}){ }^{8}$ In the law of motion, $r_{t}$ is the interest rate, $w_{t}$ is the wage rate per efficiency unit of labor, $q_{t}$ is the distribution of accidental bequests explained below, $\mathbf{1}_{\{\cdot\}}$ is an indicator function that returns 1 if the condition in \{\} holds and 0 otherwise, $I_{R}$ is set at 65 so that the household's OASI benefits are calculated based on its growth-adjusted earnings between ages 21 and 64, $\eta$ is the ratio of taxable labor income to total labor income, and $\vartheta_{\max }$ is

\footnotetext{
${ }^{8}$ For simplicity, the borrowing limit (the lowest-possible wealth level) is assumed to depend only on the household's age $i$. See Section 3.4 for the assumption of $a_{\min }^{\prime}(\mathbf{s})$.
} 
the maximum taxable earnings for the OASI program. 9 The household's wealth at the beginning of the next year, $a^{\prime}$, is adjusted by the productivity growth rate, $1+\mu$. The average historical earnings for a household at the beginning of the following year, $b^{\prime}$, are calculated as wage-indexed, and the price indexation of AIME after age 60 is reflected in the Social Security benefit function 10

\subsubsection{The Distribution of Households}

The household's problem is solved for $c, h$, and $a^{\prime}$ for all possible states 11 The household's decision rules are obtained as $c\left(\mathbf{s}, \mathbf{S}_{t} ; \boldsymbol{\Psi}_{t}, \mathbf{\Phi}_{t}\right), h\left(\mathbf{s}, \mathbf{S}_{t} ; \mathbf{\Psi}_{t}, \boldsymbol{\Phi}_{t}\right)$, and $a^{\prime}\left(\mathbf{s}, \mathbf{S}_{t} ; \boldsymbol{\Psi}_{t}, \mathbf{\Phi}_{t}\right)$, and the average historical earnings in the next year are also obtained as $b^{\prime}\left(\mathbf{s}, \mathbf{S}_{t} ; \mathbf{\Psi}_{t}, \mathbf{\Phi}_{t}\right)$ from equation (5).

Households are assumed to enter the economy at age 21 without any assets and working histories, thus,

$$
\int_{A \times B \times E} d X_{t}(21, a, b, e)=\int_{E} d X_{t}(21,0,0, e)=p_{21, t}
$$

where $p_{21, t}$ is the population of age-21 households in year $t$. In the benchmark year, which is 2014 in this paper, the growth-adjusted population of age- 21 households is normalized to unity, that is, $p_{21,2014}=1$. Let $x_{t}\left(\mathbf{s}^{\prime}\right)$ be the density function of households corresponding to $X_{t}\left(\mathbf{s}^{\prime}\right)$. Then, the law of motion of the growth-adjusted population distribution is, for $i=21, \ldots, I$,

$$
\begin{aligned}
x_{t+1}\left(\mathbf{s}^{\prime}\right) & =x_{t+1}\left(i+1, a^{\prime}, b^{\prime}, e^{\prime}\right) \\
& =\frac{\phi_{i, t}}{1+\nu} \int_{A \times B \times E} \mathbf{1}_{\left\{a^{\prime}=a^{\prime}\left(\mathbf{s}, \mathbf{S}_{t} ; \Psi_{t}, \mathbf{\Phi}_{t}\right), b^{\prime}=b^{\prime}\left(\mathbf{s}, \mathbf{S}_{t} ; \mathbf{\Psi}_{t}, \mathbf{\Phi}_{t}\right)\right\}} \pi_{i}\left(e^{\prime} \mid e\right) d X_{t}(\mathbf{s}),
\end{aligned}
$$

where $\nu$ is the long-run population growth rate, and $\pi_{i}\left(e^{\prime} \mid e\right)$ is a probability density function of working ability $e^{\prime}$ at age $i+1$ given that the working ability is $e$ at age $i i^{12}$

\footnotetext{
${ }^{9}$ In the current Social Security system, AIME is calculated based on the highest 35 years of growth-adjusted earnings. However, keeping the previous 35 highest earnings as the household's state variables will make the household problem computationally intractable. In the model economy, therefore, AIME is approximated by the growth-adjusted earnings of all ages before $I_{R}=65$.

${ }^{10}$ See Appendix D in SSA (2014) for a detailed explanation on wage indexing.

${ }^{11}$ Because the household's individual state vector, $\mathbf{s}$, includes three continuous variables, $a, b$, and $e$, the number of all possible states is infinite. Therefore, the individual state space is discretized, and the optimization problem is solved for all discretized states in each year. The aggregate state of the economy, $\mathbf{S}_{t}$, consists of a distribution function, $X_{t}(\mathbf{s})$, and thus the aggregate state space is infinitely dimensional. When there are no aggregate shocks in the model economy, however, there is a way to avoid this dimensionality problem. See Nishiyama and Smetters (2014) for the computational algorithm.

${ }^{12}$ In this paper, $x_{t}(\mathbf{s})$ and $\pi_{i}\left(e^{\prime} \mid e\right)$ are described as density functions for notational simplicity. There is a mass of households with an individual state, $(a, b, e)=\left(0, b_{\max }, 0\right)$, and $x_{t}(\mathbf{s})$ is a mass function on this point. Also, $\pi_{i}\left(e^{\prime} \mid e\right)$ is a conditional probability mass function when $e=e^{\prime}=0$.
} 


\subsubsection{The Aggregation}

Total private wealth, $W_{P, t}$, the government's net worth, $W_{G, t}$, capital stock, $K_{t}$, and labor supply in efficiency units, $L_{t}$, are calculated as

(7) $W_{P, t}=\sum_{i=21}^{I} \int_{A \times B \times E} a d X_{t}(\mathbf{s})$,

(8) $W_{G, t}=\sum_{i=21}^{I} \int_{A \times B \times E} w_{G, t} d X_{t}(\mathbf{s})=w_{G, t} \sum_{i=21}^{I} p_{i, t}$,

(9) $K_{t}=W_{P, t}+W_{G, t}$,

(10) $L_{t}=\sum_{i=21}^{I} \int_{A \times B \times E} e h\left(\mathbf{s}, \mathbf{S}_{t} ; \Psi_{t}, \mathbf{\Phi}_{t}\right) d X_{t}(\mathbf{s})$.

\subsection{The Firm}

In each year, the representative firm chooses the capital input, $\tilde{K}_{t}$, and efficiency labor input, $\tilde{L}_{t}$, to maximize its profit, taking factor prices, $r_{t}$ and $w_{t}$, as given. Thus, the firm's optimization problem is

(11) $\max _{\tilde{K}_{t}, \tilde{L}_{t}} F\left(\tilde{K}_{t}, \tilde{L}_{t}\right)-\left(r_{t}+\delta\right) \tilde{K}_{t}-w_{t} \tilde{L}_{t}$,

where $F(\cdot)$ is a constant-returns-to-scale production function, $F\left(\tilde{K}_{t}, \tilde{L}_{t}\right)=A \tilde{K}_{t}^{\theta} \tilde{L}_{t}^{1-\theta}$, with total factor productivity $A$, and $\delta$ is the depreciation rate of capital. The firm's profit-maximizing conditions are

$$
F_{K}\left(\tilde{K}_{t}, \tilde{L}_{t}\right)=r_{t}+\delta, \quad F_{L}\left(\tilde{K}_{t}, \tilde{L}_{t}\right)=w_{t}
$$

and the factor markets are cleared when

$$
K_{t}=\tilde{K}_{t}, \quad L_{t}=\tilde{L}_{t}
$$

\subsection{The Government}

The government policy schedule, $\boldsymbol{\Psi}_{t}$, as of year $t$ is assumed to be credible. The government collects taxes and makes its consumption and transfer spending as scheduled in $\Psi_{t}$. In addition, the government collects wealth left by deceased households (accidental bequests) and distributes it uniformly to all workingage households. 


\subsubsection{The Government's Revenue and Expenditure}

The government's income tax revenue, $T_{I, t}$, payroll tax revenue for Social Security, $T_{P, t}$, and consumption (or other) tax revenue, $T_{C, t}$, are calculated as

$$
\begin{aligned}
& \text { (14) } T_{I, t}\left(\varphi_{t}\right)=\sum_{i=21}^{I} \int_{A \times B \times E} \tau_{I, t}\left(w_{t} e h\left(\mathbf{s}, \mathbf{S}_{t} ; \mathbf{\Psi}_{t}, \boldsymbol{\Phi}_{t}\right), r_{t} a, \operatorname{tr}_{S S, t}(i, b) ; \varphi_{t}\right) d X_{t}(\mathbf{s}), \\
& \text { (15) } T_{P, t}\left(\tau_{O, t}, \tau_{D, t}, \tau_{H, t}\right)=\sum_{i=21}^{I} \int_{A \times B \times E} \tau_{P, t}\left(w_{t} \operatorname{eh}\left(\mathbf{s}, \mathbf{S}_{t} ; \mathbf{\Psi}_{t}, \mathbf{\Phi}_{t}\right) ; \tau_{O, t}, \tau_{D, t}, \tau_{H, t}\right) d X_{t}(\mathbf{s}), \\
& \text { (16) } T_{C, t}\left(\tau_{C, t}\right)=\sum_{i=21}^{I} \int_{A \times B \times E} \tau_{C, t} c\left(\mathbf{s}, \mathbf{S}_{t} ; \mathbf{\Psi}_{t}, \mathbf{\Phi}_{t}\right) d X_{t}(\mathbf{s}),
\end{aligned}
$$

where $\varphi_{t}$ is one of the parameters of the income tax function, and $\left(\tau_{O, t}, \tau_{D, t}, \tau_{H, t}\right)$ is a vector of the OASI, DI, and HI payroll tax rates. The government's consumption spending, $C_{G, t}$, non-Social Security transfer spending, $T R_{L S, t}$, and Social Security transfer spending, $T R_{S S, t}$, are

$$
\begin{aligned}
& \text { (17) } C_{G, t}\left(c_{G, t}\right)=\sum_{i=21}^{I} \int_{A \times B \times E} c_{G, t} d X_{t}(\mathbf{s})=c_{G, t} \sum_{i=21}^{I} p_{i, t}, \\
& \text { (18) } T R_{L S, t}\left(\operatorname{tr}_{L S, t}\right)=\sum_{i=21}^{I} \int_{A \times B \times E} \operatorname{tr}_{L S, t} d X_{t}(\mathbf{s})=\operatorname{tr}_{L S, t} \sum_{i=21}^{I} p_{i, t}, \\
& \text { (19) } T R_{S S, t}\left(\psi_{O, t}, \psi_{D, t}, \psi_{H, t}\right)=\sum_{i=21}^{I} \int_{A \times B \times E} \operatorname{tr}_{S S, t}\left(i, b ; \psi_{O, t}, \psi_{D, t}, \psi_{H, t}\right) d X_{t}(\mathbf{s}),
\end{aligned}
$$

where $\psi_{O, t}$ is a parameter of the OASI benefit function, and $\psi_{D, t}$ and $\psi_{H, t}$ are adjustment factors of DI and HI benefits, respectively.

For simplicity, the government is assumed to collect remaining wealth held by deceased households at the end of year $t$ and distributes it in a lump-sum manner in the same year. Because there are no aggregate shocks in the model economy, the government can perfectly predict the sum of accidental bequests during the year. The government revenue from these accidental bequests, $Q_{t}$, is calculated as

$$
Q_{t}=\sum_{i=21}^{I} \int_{A \times B \times E}\left(1-\phi_{i, t}\right)(1+\mu) a^{\prime}\left(\mathbf{s}, \mathbf{S}_{t} ; \Psi_{t}, \mathbf{\Phi}_{t}\right) d X_{t}(\mathbf{s})
$$

Suppose that the government redistributes the accidental bequests uniformly to all working-age house- 
holds ${ }^{13}$ Then, for $i=21, \ldots, I_{R}-1$, the bequest received by each working-age household is

(21) $q_{t}(i)=\left(\sum_{i=21}^{I_{R}-1} \int_{A \times B \times E} d X_{t}(\mathbf{s})\right)^{-1} Q_{t}$.

The government budget satisfies the following constraint,

$$
\begin{aligned}
(1+\mu)(1+\nu) W_{G, t+1} & =\left(1+r_{t}\right) W_{G, t}+T_{I, t}\left(\varphi_{t}\right)+T_{P, t}\left(\tau_{O, t}, \tau_{D, t}, \tau_{H, t}\right)+T_{C, t}\left(\tau_{C, t}\right) \\
& -C_{G, t}\left(c_{G, t}\right)-T R_{L S, t}\left(\operatorname{tr}_{L S, t}\right)-T R_{S S, t}\left(\psi_{O, t}, \psi_{D, t}, \psi_{H, t}\right) .
\end{aligned}
$$

\subsection{Recursive Competitive Equilibrium}

This section defines a recursive competitive equilibrium for the model economy.

Definition of Recursive Competitive Equilibrium: Let $\mathbf{s}=(i, a, b, e)$ be the individual state of households, let $\mathbf{S}_{t}=\left(X_{t}(\mathbf{s}), w_{G, t}\right)$ be the state of the economy in year $t$, let $\mathbf{\Psi}_{t}$ be the government policy schedule committed at the beginning of year $t$,

$$
\boldsymbol{\Psi}_{t}=\left\{c_{G, s}, \operatorname{tr}_{L S, s}, \tau_{I, s}(\cdot), \tau_{P, s}(\cdot), \operatorname{tr}_{S S, s}(\cdot), \tau_{C, s}, w_{G, s+1}\right\}_{s=t}^{\infty},
$$

and let $\boldsymbol{\Phi}_{t}=\left\{\left(p_{i, s}\right)_{i=0}^{I},\left(\phi_{i, s}\right)_{i=0}^{I}\right\}_{s=t}^{\infty}$ be the population projection and corresponding survival rates as of the beginning of year $t$. A time series of factor prices and the government policy variables,

$$
\boldsymbol{\Omega}_{t}=\left\{r_{s}, w_{s}, q_{s}, c_{G, s}, \operatorname{tr}_{L S, s}, \varphi_{s},\left(\tau_{O, s}, \tau_{D, s}, \tau_{H, s}\right),\left(\psi_{O, s}, \psi_{D, s}, \psi_{H, s}\right), \tau_{C, s}, w_{G, s+1}\right\}_{s=t}^{\infty},
$$

the value functions of households, $\left\{v\left(\mathbf{s}, \mathbf{S}_{s} ; \mathbf{\Psi}_{s}, \mathbf{\Phi}_{s}\right)\right\}_{s=t}^{\infty}$, the decision rules of households,

$$
\mathbf{d}\left(\mathbf{s}, \mathbf{S}_{s} ; \boldsymbol{\Psi}_{s}, \boldsymbol{\Phi}_{s}\right)=\left\{c\left(\mathbf{s}, \mathbf{S}_{s} ; \boldsymbol{\Psi}_{s}, \boldsymbol{\Phi}_{s}\right), h\left(\mathbf{s}, \mathbf{S}_{s} ; \mathbf{\Psi}_{s}, \boldsymbol{\Phi}_{s}\right), a^{\prime}\left(\mathbf{s}, \mathbf{S}_{s} ; \mathbf{\Psi}_{s}, \boldsymbol{\Phi}_{s}\right)\right\}_{s=t}^{\infty},
$$

and the distribution of households, $\left\{X_{s}(\mathbf{s})\right\}_{s=t}^{\infty}$, are in a recursive competitive equilibrium if, for all $s=$ $t, \ldots, \infty$, each household solves the optimization problem of equations (1) through (5), taking $\mathbf{S}_{s}, \mathbf{\Psi}_{s}$, and $\boldsymbol{\Phi}_{s}$ as given; the firm solves its profit maximization problem of equations $(11)$ and $(12)$; the government policy schedule satisfies equations (14) through (22); and the goods and factor markets clear, thus

\footnotetext{
${ }^{13}$ Uniformly distributing the accidental bequests is a common simplification in the literature. Conesa, Kitao, and Krueger (2009) assume that all surviving households receive accidental bequests uniformly. Nishiyama and Smetters (2007) assume that workingage surviving households receive uniform accidental bequests with probability $\eta$, where $\eta$ is the ratio of deceased households to the working-age surviving households.
} 
these satisfy equations (7) through $(10)$ and equation $(13)$. The economy is in a stationary (steady-state) equilibrium - thus, on the balanced-growth path—if in addition, $\mathbf{S}_{s}=\mathbf{S}_{s+1}, \boldsymbol{\Psi}_{s+1}=\boldsymbol{\Psi}_{s}$, and $\boldsymbol{\Phi}_{s+1}=\boldsymbol{\Phi}_{s}$ for all $s=t, \ldots, \infty 14$

\subsection{Social Welfare Measures}

Suppose that the economy is in the initial equilibrium in year $t=0$ and that the government introduces a new policy at the beginning of year 1 . Then, the rest-of-the-lifetime value of a household of state $\mathbf{s}=$ $(i, a, b, e)$ is denoted by $v\left(\mathbf{s}, \mathbf{S}_{0} ; \mathbf{\Psi}_{0}, \boldsymbol{\Phi}_{0}\right)$ before the policy change and $v\left(\mathbf{s}, \mathbf{S}_{t} ; \mathbf{\Psi}_{t}, \boldsymbol{\Phi}_{t}\right)$ for $t=1, \ldots, \infty$ after the policy change.

\subsubsection{Consumption Equivalence}

Under the veil-of-ignorance welfare measure, welfare gains or losses of newborn households (age $i=$ 21) at the beginning of $t=1, \ldots, \infty$ are calculated by uniform percent changes, $\lambda_{21, t}$, in the baseline consumption path that would make their expected lifetime utility equivalent to the expected utility after the policy change, that is 15

$$
\lambda_{21, t}=\left[\left(\frac{E v\left(\mathbf{s}_{21}, \mathbf{S}_{t} ; \mathbf{\Psi}_{t}, \mathbf{\Phi}_{t}\right)}{E v\left(\mathbf{s}_{21}, \mathbf{S}_{0} ; \mathbf{\Psi}_{0}, \mathbf{\Phi}_{0}\right)}\right)^{\frac{1}{\alpha(1-\gamma)}}-1\right] \times 100
$$

Similarly, the average welfare changes of households of age $i=22, \ldots, I$ at the time of the policy change $(t=1)$ are calculated by the uniform percent changes, $\lambda_{i, 1}$, required in the baseline consumption path so that the rest of the lifetime value would be equal to the rest of the lifetime value after the policy change, that is,

$$
\lambda_{i, 1}=\left[\left(\frac{E v\left(\mathbf{s}_{i}, \mathbf{S}_{1} ; \mathbf{\Psi}_{1}, \mathbf{\Phi}_{1}\right)}{E v\left(\mathbf{s}_{i}, \mathbf{S}_{0} ; \mathbf{\Psi}_{0}, \mathbf{\Phi}_{0}\right)}\right)^{\frac{1}{\alpha(1-\gamma)}}-1\right] \times 100
$$

Note that $\lambda_{i, 1}$ for $i=I, \ldots, 21$ shows the cohort-average welfare changes of all current households alive at the time of the policy change, and $\lambda_{21, t}$ for $t=2, \ldots, \infty$ shows the cohort-average welfare changes of all future households.

\footnotetext{
${ }^{14}$ To solve the model for a stationary equilibrium, the population distribution needs to be constant, after growth adjustment, in the long run. Even if this paper assumes the fertility rates to be constant after 2100, it takes several hundred years before the population distribution completely stabilizes because the number of newborn babies depends on the population distribution of women ages $15-50$.

${ }^{15}$ The calculation of $\lambda_{i, t}$ depends on the period utility function. With the Cobb-Douglas and CRRA utility function, equation 6, when consumption proportionally increases by $\lambda_{i, t} / 100$, the household value increases by $\left(1+\lambda_{i, t} / 100\right)^{\alpha(1-\gamma)}-1$.
} 


\subsubsection{Compensating Variations}

The compensating variation of a household with individual state $\mathbf{s}=(i, a, b, e)$ is a one-time negative wealth transfer, $c v(\mathbf{s})$, that restores the baseline welfare level in the alternative economy after the policy change. The compensating variations of newborn households (age $i=21$ ) at the beginning of $t=1, \ldots, \infty$ are calculated as $c v\left(\mathbf{s}_{21}, \mathbf{S}_{t} ; \mathbf{\Psi}_{t}, \mathbf{\Phi}_{t}\right)$ such that

$$
v\left(21, a-c v\left(\mathbf{s}_{21}, \mathbf{S}_{t} ; \mathbf{\Psi}_{t}, \mathbf{\Phi}_{t}\right), b, e, \mathbf{S}_{t} ; \boldsymbol{\Psi}_{t}, \boldsymbol{\Phi}_{t}\right)=v\left(21, a, b, e, \mathbf{S}_{0} ; \mathbf{\Psi}_{0}, \boldsymbol{\Phi}_{0}\right),
$$

and the compensating variations of age $i=22, \ldots, I$ at the time of the policy change $(t=1)$ are calculated as $c v\left(\mathbf{s}_{i}, \mathbf{S}_{1} ; \mathbf{\Psi}_{1}, \mathbf{\Phi}_{1}\right)$ such that

$$
v\left(i, a-c v\left(\mathbf{s}_{i}, \mathbf{S}_{1} ; \boldsymbol{\Psi}_{1}, \mathbf{\Phi}_{1}\right), b, e, \mathbf{S}_{1} ; \boldsymbol{\Psi}_{1}, \boldsymbol{\Phi}_{1}\right)=v\left(i, a, b, e, \mathbf{S}_{0} ; \boldsymbol{\Psi}_{0}, \boldsymbol{\Phi}_{0}\right) .
$$

The average growth-adjusted compensating variations in wealth by age cohort are calculated as

$$
\begin{aligned}
& \lambda_{21, t}^{C V}=\int_{A \times B \times E} c v\left(21, a, b, e, \mathbf{S}_{t} ; \mathbf{\Psi}_{t}, \mathbf{\Phi}_{t}\right) d X_{t}\left(\mathbf{s}_{21}\right) \times \frac{1}{p_{21, t}}, \\
& \lambda_{i, 1}^{C V}=\int_{A \times B \times E} c v\left(i, a, b, e, \mathbf{S}_{1} ; \mathbf{\Psi}_{1}, \mathbf{\Phi}_{1}\right) d X_{1}\left(\mathbf{s}_{i}\right) \times \frac{1}{p_{i, 1}},
\end{aligned}
$$

for $t=1, \ldots, \infty$ and $i=22, \ldots, I$.

\section{Calibration}

The current U.S. population is aging, that is, the population distribution is not stationary. So, a stationary equilibrium in an overlapping-generations economy cannot, in general, describe an economy with the aging population. This section, therefore, constructs the aging-population baseline economy as an equilibrium transition path between 1975 and 2200 and calibrates the model to the 2014 U.S. economy such that the model economy in 2014 (on the equilibrium transition path) is consistent with the 2014 U.S. economy in terms of macroeconomic statistics and population distribution. Because the government's fiscal policy is not sustainable under the aging-population assumption, the baseline economy assumes that the government cuts (or increases) its consumption so that the government's debt-per capita stays at the same level after the growth adjustment ${ }^{16}$ Because the government's consumption does not affect the household's decision in

\footnotetext{
${ }^{16}$ In other words, the government's debt per capita is assumed to grow at the same rate of the labor augmenting productivity growth rate, $\mu$. This assumption assures that the debt-to-GDP ratio stays constant in the long run.
} 
this model economy, the aging baseline economy incorporates the effect of the demographic changes without any feedback effects from the government's fiscal policy changes. This paper calls the 2014 economy in the aging baseline economy the benchmark economy and uses it as the benchmark for comparison in the policy experiments.

\subsection{Population Projection}

This paper uses Social Security Administration's population projections-alternative 2 (intermediate scenario), alternative 1 (low-cost scenario), and alternative 3 (high-cost scenario)-provided for the 2014 trustees report. These population projections consist of the historical population by age and gender over 1941-2012 and the projected populations by age and gender over 2013-2100, but these projections show the population of ages 100 and older as that of one age group (100+).

To incorporate SSA's population projection to the model economy, this paper first imputes the population distribution and mortality rates of ages 100-120 from the combined population of ages $100+$. Let $\hat{p}_{i, t}^{j}$ be the population of age $i$ and gender $j$ in year $t$, and let $q_{i}^{j}$ be the mortality rate of age $i$ and gender $j$ in the 2010 period life table (Table 4.C6) in SSA (2015). Then, for $i=100, \ldots, 120, j=1$ (male) and 2 (female), and $t=1941, \ldots, 2100$, the population of ages 100-120 by age, gender, and year, this paper obtains $\hat{p}_{i, t}^{j}$ as

$$
\hat{p}_{i, t}^{j}= \begin{cases}\left(1-\xi_{t-1}^{j} q_{i-1}^{j}\right) \hat{p}_{i-1, t}^{j} & \text { if } t=1941 \\ \left(1-\xi_{t-1}^{j} q_{i-1}^{j}\right) \hat{p}_{i-1, t-1}^{j} & \text { if } t>1941\end{cases}
$$

where $\xi_{t-1}^{j}$ is a time-and-gender-specific mortality rate adjustment factor that satisfies

$$
\hat{p}_{100+, t}^{j}=\sum_{i=100}^{120} \hat{p}_{i, t}^{j} .
$$

Then, this paper obtains the population of age $i$ in year $t$ as $\hat{p}_{i, t}=\hat{p}_{i, t}^{1}+\hat{p}_{i, t}^{2}$ for $i=100, \ldots, 120$ and $t=$ $1941, \ldots, 2100$ and calculates the corresponding survival rate as $\phi_{i, t}=\hat{p}_{i+1, t+1} / \hat{p}_{i, t}$ for $i=99, \ldots, 119$ and $t=1941, \ldots, 2099$ with $\phi_{120, t}=0$ for all $t$.

This paper next extrapolates the population and the survival rate by age beyond 2100 . In this extrapolation, for simplicity, this paper keeps the survival rate by age at the same level beyond 2099, that is, $\phi_{i, t}=\phi_{i, t-1}$ for $i=0, \ldots, 120$ and $t=2100, \ldots, 2200$. The paper also assumes the age-specific fertility rates to be constant beyond 2100. More specifically, this paper estimates the population of age-0 (newborn) 
Figure 1: The Old-Age Dependency Ratio and the Share of Working-Age Population

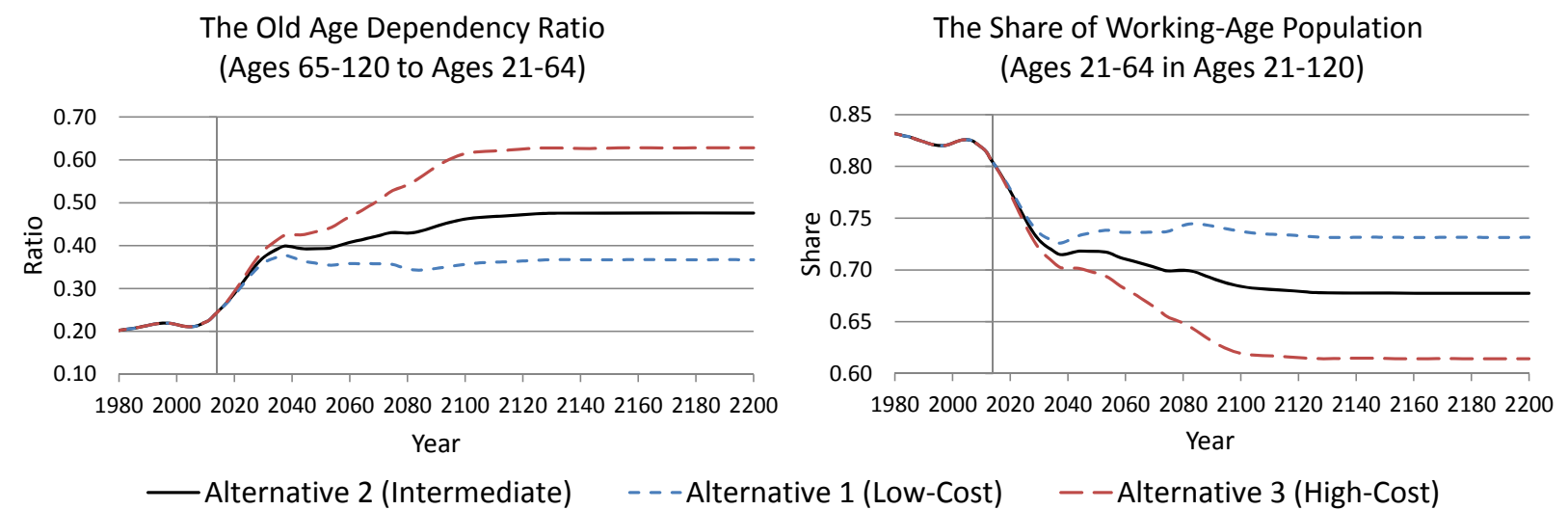

Source: Author's calculations from the population projections for Social Security Administration (2014).

babies, $\hat{p}_{0, t}$, for $t=2101, \ldots, 2200$ as

$$
\begin{aligned}
\hat{p}_{0, t}=\zeta_{2100} & \left(0.041 \sum_{i=15}^{19} \hat{p}_{i, t}^{2}+0.103 \sum_{i=20}^{24} \hat{p}_{i, t}^{2}+0.115 \sum_{i=25}^{29} \hat{p}_{i, t}^{2}+0.099 \sum_{i=30}^{34} \hat{p}_{i, t}^{2}\right. \\
& \left.+0.047 \sum_{i=35}^{39} \hat{p}_{i, t}^{2}+0.010 \sum_{i=40}^{44} \hat{p}_{i, t}^{2}+0.001 \sum_{i=45}^{49} \hat{p}_{i, t}^{2}\right)
\end{aligned}
$$

where $\zeta_{2100}$ is the fertility rate adjustment factor for 2100 such that the above equation holds in 2100 . The age-specific fertility rates used in the above equation are those for 2008 in United Nations (2013).

Then this paper obtains the long-run population growth rate, $\nu$, as

$$
\nu=\frac{\sum_{i=0}^{120} \hat{p}_{i, 2200}}{\sum_{i=0}^{120} \hat{p}_{i, 2199}}-1=0.003217 \text { (alt. 2), } 0.007321 \text { (alt. 1), } \quad-0.001454 \text { (alt. 3), }
$$

and calculates the growth-adjusted population by age, $p_{i, t}$, with $p_{21,2014}$ normalized to unity, as

$$
p_{i, t}=\frac{1}{(1+\nu)^{t-2014}} \frac{\hat{p}_{i, t}}{\hat{p}_{21,2014}},
$$

for $i=21, \ldots, 120$ and $t=1975, \ldots, 2200$.

Figure 1 shows the old-age dependency ratio (the ratio of households ages 65 and older to those ages between 21 and 64) and the share of working age population (the share of households ages between 21 and 64 in those ages 21 and older) between 1980 and 2200. The old-age dependency ratio goes up from 0.244 in 2014 to $0.398(0.375,0.425)$ in 2039 and $0.476(0.367,0.628)$ in the long run under alternative 2 (alternative 
1, alternative 3). The increase in this old-age dependency ratio explains the increase in the cost of the Social Security program in the future. The share of working-age population in total adult population goes down from 0.804 in 2014 to $0.715(0.727,0.702)$ in 2039 and $0.677(0.731,0.614)$ in the long run under alternative 2 (alternative 1, alternative 3). The declines in the share of working-age population explains the decreases in the labor supply per capita and gross domestic output per capita in the future.

\subsection{Calibration Strategy}

Because the current U.S. population distribution is aging and thus not stationary, it is impossible to construct the 2014 benchmark economy as a stationary equilibrium. So, this paper constructs the agingpopulation baseline economy as an equilibrium transition path between 1975 and 2200 by the following procedure.

1. This paper first solves the model for a stationary equilibrium with the population distribution in 1975 , where the households in the model economy falsely believe that the population distribution does not change and the economy is stationary, although the model calculates aggregate variables by using the non-stationary 1975 population distribution.

2. This paper next solves the model for a stationary equilibrium with the population distribution in 2200 . The population projection in 2200 is constructed to be stationary ${ }^{17}$

3. This paper then solves the model for an equilibrium transition path between 1975 and 2200 using one of population projections as well as historical population. The households in the model economy realize, at the beginning of 1975 , that the population distribution is not stationary, and they precisely project the changes in fertility rates and mortality rates through 2200 .

This paper repeats Step 1 through Step 3 to find a set of preference and policy parameters that make the 2014 model economy on the equilibrium transition path consistent with the 2014 U.S. economy in terms macroeconomic and fiscal policy statistics. The current-law fiscal policy is not sustainable in the presence of the aging population. Therefore, as explained above, this paper assumes that the government adjusts its consumption to keep its government's net worth per capita at the 2014 level after the productivity growth adjustment.

Table 1 shows the values of main preference and technology parameters in the aging-population baseline economy over 1975-2200 under SSA's population projections alternative 2 (intermediate scenario), alterna-

\footnotetext{
${ }^{17}$ Because this paper keeps both the mortality rates and age-specific fertility rates constant after 2100 , the population distribution in 2200 is approximately stationary.
} 
Table 1: Main Parameter Values of the Aging-Population Baseline Economies

\begin{tabular}{lrrrll}
\hline \hline Parameter & & Alt. 2 & Alt. 1 & Alt. 3 & Comment / Target \\
\hline Demographics & $I$ & 120 & 120 & 120 & \\
Maximum age & & 80 & 80 & 80 & \\
Maximum age households can work & $I_{R}$ & 65 & 65 & 65 & Medicare eligibility age \\
Minimum age of elderly households & $\mu$ & 0.0150 & 0.0150 & 0.0150 & Real GDP per capita in 1989-2014 \\
Productivity growth rate & $\nu$ & 0.0032 & 0.0073 & -0.0015 & Population growth in 2200 \\
Long-run population growth rate & & 51.307 & 51.307 & 51.307 & When $p_{21, t}=1.0$ in 2014 \\
Total population (ages 21-120) in 2014 & & 41.241 & 41.241 & 41.241 & \\
Working-age population in 2014 & & & & & \\
Preferences & $\beta$ & 1.0084 & 1.0087 & 1.0081 & $K_{t} / Y_{t}=2.92$ in 2014 \\
Discount factor & $\tilde{\beta}$ & 0.9872 & 0.9875 & 0.9869 & $\tilde{\beta}=\beta(1+\mu)^{\alpha(1-\gamma)}$ \\
Growth-adjusted discount factor & $\gamma$ & 3.0000 & 3.0000 & 3.0000 & \\
Coefficient of relative risk aversion & $\alpha$ & 0.7148 & 0.7150 & 0.7148 & Frisch elasticity 0.5 in 2014 \\
Share parameter of consumption & & & & & \\
\hline Production technology and wage process & & 0.4100 & 0.4100 & 0.4100 & Labor share 0.59 in 2010-2014 \\
Share parameter of capital stock & $\delta$ & 0.0804 & 0.0804 & 0.0804 & $r_{t}=0.06$ in 2014 \\
Depreciation rate of capital stock & $A$ & 0.8798 & 0.8798 & 0.8798 & $w_{t}=1.0$ in 2014 \\
Total factor productivity & $\rho$ & 0.9500 & 0.9500 & 0.9500 & \\
Auto correlation parameter of log wage & $\sigma$ & 0.2600 & 0.2600 & 0.2600 & Var. of log earnings in 2013 SCF \\
Standard deviation of log wage shocks & $\bar{e}_{i}$ & & & & Estimated by OLS with 2013 SCF \\
Average hourly wage by age & & & & &
\end{tabular}

Note: This baseline calibration uses the population projections alternative 2 (intermediate scenario), alternative 1 (low-cost scenario), and alternative 3 (high-cost scenario) for Social Security Administration (2014).

tive 1 (low-cost scenario), and alternative 3 (high-cost scenario); and Table 2 (on page 24) shows the values of the government policy parameters in the same three economies. The rest of this section explains the parameters under the population projection alternative 2 .

\subsection{Demographics}

The maximum possible age of households in the model economy, $I$, is 120 . This paper calls households of ages 21 to 64 working-age households, and households of ages $I_{R}=65$ and older elderly households, even though they can possibly work until age 80. When this paper normalizes the population of age-21 households in 2014 to unity, the total population and the working-age population are 51.31 and 41.24 , respectively. For simplicity, the total population is that of ages 21 and older in this paper, and it excludes the population of ages between 0 and 20. Households in the model economy are assumed to be a mixture of married (50\%) and single (50\%) households ${ }^{18}$ The labor-augmenting productivity growth rate, $\mu$, is set at $1.5 \%$, which is close to the average growth rate, $1.48 \%$, of real GDP per capita over the past 25 years, 1989-

\footnotetext{
${ }^{18}$ According to Table 1 in Vespa, Lewis, and Kreider (2013), which is constructed from the U.S. Census Bureau's 2011 American Community Survey, $48.3 \%$ of all households and 51.4\% of households ages 25 to 64 are married households in 2011.
} 
Figure 2: Population Growth Rate by Year and Long-Run Growth Rate

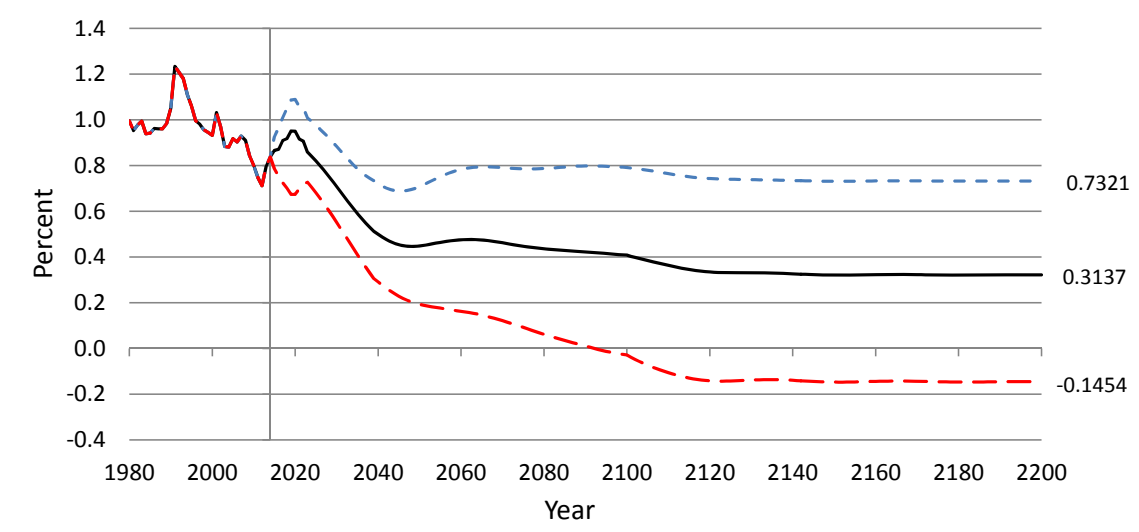

_-Alternative $2 \quad--$-Alternative 1 (Low-Cost) - - Alternative 3 (High-Cost)

Source: Author's calculations from the population projections for Social Security Administration (2014).

2014. The long-run population growth rate, $\nu$, is set at $0.3137 \%$ as explained above, although the population grows faster in the short and medium run. Figure 2 shows the population growth rates in SSA's projection and the long-run population growth rate, $\nu$, under the projection alternative 2 as well as the growth rates under alternatives 1 and 3 .

\subsection{Preferences}

The household's period utility function is a combination of Cobb-Douglas and constant relative risk aversion,

$$
u(c, h)=\frac{\left[c^{\alpha}(1-h)^{1-\alpha}\right]^{1-\gamma}}{1-\gamma},
$$

which is consistent with a growth economy 19 The coefficient of relative risk aversion, $\gamma$, for the combination of consumption and leisure is set at 3.0, which is roughly in the middle of the range assumed in macroeconomic public finance literature 20 The share parameter of consumption, $\alpha$, is set at 0.7148 so that the Frisch elasticity of working hours of the average household (a household whose working hours are the average of those of all working-age households, $\bar{h}=0.6182$ ) is 0.5 in the 2014 benchmark economy, where

\footnotetext{
${ }^{19}$ When the period utility function is additively separable, as in $u(c, h)=f(c)-g(h)$, then the utility function is consistent with a balanced-growth path-the average working hours are unchanged in a steady state even though productivity is rising-only if $f(c)$ is proportional to $\ln c$.

${ }^{20}$ For example, Domeij and Heathcote (2004) use 1.0, İmrohoroğlu, İmrohoroğlu, and Joines (1995) use 2.0, and Auerbach and Kotlikoff (1987) and Conesa, Kitao, and Krueger (2009) use 4.0.
} 
the Frisch elasticity is calculated as

$$
\frac{1-\bar{h}}{\bar{h}} \frac{1-\alpha(1-\gamma)}{\gamma}=0.5
$$

The discount factor, $\beta$, of households is set at 1.0084 so that the capital-output ratio in the 2014 benchmark economy is equal to the ratio, 2.92, in 2014 in the national income and product account (NIPA) data. Then, this paper obtains the growth-adjusted discount factor as

$$
\tilde{\beta}=\beta(1+\mu)^{\alpha(1-\gamma)}=0.9872 .
$$

This paper assumes that the household's minimum wealth level $(\leq 0)$ depends only on its age, as $a^{\prime} \geq$ $a_{\min }^{\prime}(i, a, b, e)=a_{\min }(i+1)$, and

$$
a_{\min }(i)= \begin{cases}0 & \text { if } \quad i=21 \text { or } I+1 \\ {\left[(1+\mu) a_{\min }(i+1)-0.15 \bar{w} e_{\min }(i) h_{\max }\right] /(1+\bar{r})} & \text { if } \quad i=22, \ldots, I\end{cases}
$$

where $e_{\min }(i)$ is the lowest working ability for age $i$, and where $\bar{r}, \bar{w}$, and $\bar{h}$ are the interest rate, the wage rate, and the average working hours, respectively, in the 2014 benchmark economy. One might expect minimum assets to be set at what a household could repay under the worst possible realizations for working ability. However, this paper multiplies labor income with the lowest working ability and average working hours (repaying ability) by 0.15 to align household debt to the U.S. economy. According to the 2013 Survey of Consumer Finances (SCF) (Federal Reserve Board, 2014), 11.3\% of households (ages 21-99) have negative net worth with average net debt $\$ 32,292$, and average debt per household is $\$ 3,659$. In the 2014 benchmark economy, $20.2 \%$ of households have negative wealth with average net debt $\$ 18,257$, and average debt per household is $\$ 3,688$.

\subsection{The Production Technology and the Wage Process}

The production function of the representative firm is one of Cobb-Douglas,

$$
Y=F(K, L)=A K^{\theta} L^{1-\theta}
$$

The share parameter of capital stock, $\theta$, is set equal to 0.41 , which reflects 1 minus the average labor income share, $w_{t} L_{t} / Y_{t}=0.59$, for 2009-2013 in the NIPA data. When the capital-output ratio, $K_{t} / Y_{t}$, is 2.92, the gross rate of return to capital is $r_{t}+\delta=\theta Y_{t} / K_{t}=0.41 / 2.92=0.1404$ or $14.04 \%$. The depreciation 
rate of capita, $\delta$, is set at 0.0804 so that the real rate of return to capital, $r_{t}$, is 0.06 or $6.0 \%$ in the 2014 benchmark economy. Total factor productivity, $A$, is fixed at 0.8798 so that the average wage rate, $w_{t}$, is normalized to unity in the benchmark economy.

The working ability, $e_{i}$, of an age $i$ household in the model economy is assumed to satisfy

$$
\ln e_{i}=\ln \bar{e}_{i}+\ln z_{i}
$$

for $i=21, \ldots, 80$, where $w_{t} \bar{e}_{i}$ is the average wage rate of age $i$ households in year $t$, and $z_{i}$ is the persistent shock that follows an AR(1) process,

$$
\ln z_{i}=\rho \ln z_{i-1}+\epsilon_{i}
$$

for $i=21, \ldots, 80$. The temporary shock, $\epsilon_{i}$, is normally distributed, $\epsilon_{i} \sim N\left(-\frac{1}{2} \sigma^{2}, \sigma^{2}\right)$, and the initial distribution of the $\log$-persistent shock satisfies $\ln z_{20} \sim N\left(-\frac{1}{2} \sigma_{\ln z_{20}}^{2}, \sigma_{\ln z_{20}}^{2}\right)$.

The average working ability, $\bar{e}_{i}$, for ages 21 to 80 is constructed from the 2013 SCF (Federal Reserve Board, 2014). This paper first calculates the unconditional average hourly wage and the average hourly wage given earnings are strictly positive for ages 21 to 80 in the $2013 \mathrm{SCF}^{21}$ Then, this paper estimates the average hourly wage (working ability) by age by using ordinary least squares with the weighted average of the unconditional and conditional average hourly wages. Thus, this paper implicitly assumes that some households do not work because their working ability is very low, but other households, especially elderly households, decide not to work even though their working ability is high. Figure 3 shows the average hourly wages calculated from the 2013 SCF and the estimated (smoothed) average hourly wage in the model economy. The average of $\bar{e}_{i}$ for ages 21 to 64 is also normalized to unity in the model economy.

The autocorrelation parameter, $\rho$, of the log-persistent shock is set at 0.95 , which is approximately in the middle of the range in the previous literature ${ }^{22}$ Given the initial variance, $\sigma_{\ln z_{20}}^{2}$, the variance of $\log$ persistent shock, $\ln z_{i}$, is calculated recursively as

$$
\sigma_{\ln z_{i}}^{2}=\rho^{2} \sigma_{\ln z_{i-1}}^{2}+\sigma^{2}
$$

for $i=21, \ldots, 80$. To align the wage process to the U.S. data, the standard deviation, $\sigma$, of the transitory

\footnotetext{
${ }^{21}$ To calculate the unconditional average hourly wage, this paper assumes that the hourly wage is zero when the household is not working. So, the unconditional average is the lower bound of the average potential wage, whereas the conditional average is the upper bound of the average potential wage.

${ }^{22}$ For example, Domeij and Heathcote (2004) use 0.90, Huggett (1996) uses 0.96, and Conesa, Kitao, and Krueger (2009) use 0.98 .
} 
Figure 3: The Average Hourly Wage by Age

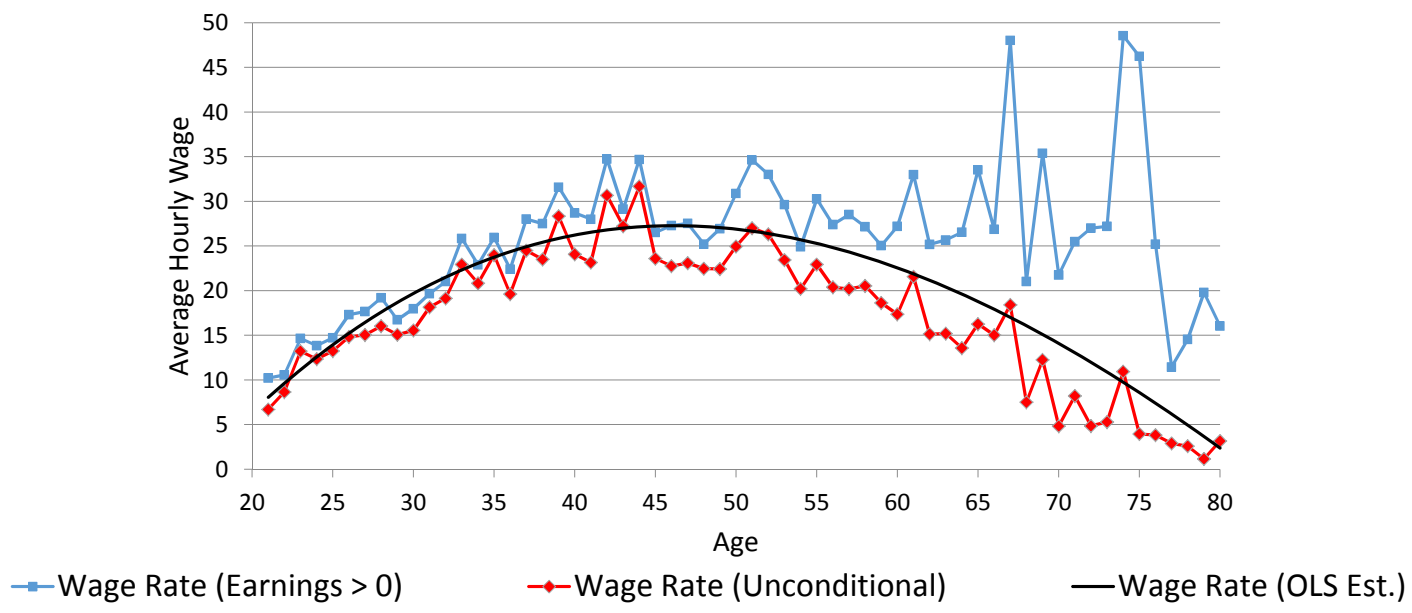

Sources: Author's calculations from the 2013 Survey of Consumer Finances (Federal Reserve Board, 2014).

shock, $\epsilon_{i}$, is set at 0.26 , and the initial variance, $\sigma_{\ln z_{20}}^{2}$, of the log-persistent shock is set at a fraction of its limiting variance,

$$
\sigma_{\ln z_{20}}^{2}=0.4 \lim _{i \rightarrow \infty} \sigma_{\ln z_{i}}^{2}=0.4 \times \frac{\sigma^{2}}{1-\rho^{2}}=0.4 \times 0.6933=0.2773
$$

The number $0.4<1$ is chosen so that the variance of log earnings increases with the age of the household. Figure 4 shows that the variances of log labor income calculated using the 2013 SCF (Federal Reserve Board, 2014) and those in the 2014 benchmark economy are quite similar 23

This paper uses the Rouwenhorst method (Rouwenhorst, 1995) to discretize the log-persistent shock for each age and construct the Markov transition matrix by age. The unconditional probability distribution of the 7 nodes is

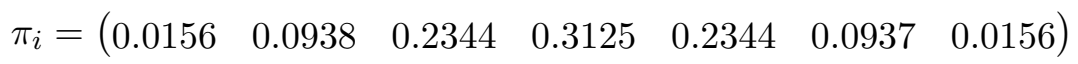

for $i=21, \ldots, 80$, and the Markov transition matrix of an age $i$ household, $\Pi_{i}=\left[\pi\left(e_{i+1}^{j^{\prime}} \mid e_{i}^{j}\right)\right]$, that

\footnotetext{
${ }^{23}$ Although the variance of $\log$ working ability, $\sigma_{\ln z_{i}}^{2}$, is assumed to strictly increase with age, the variance of log labor income is not necessarily monotone in the model economy, because working hours are endogenous.
} 
Figure 4: The Variance of Log Labor Income by Age

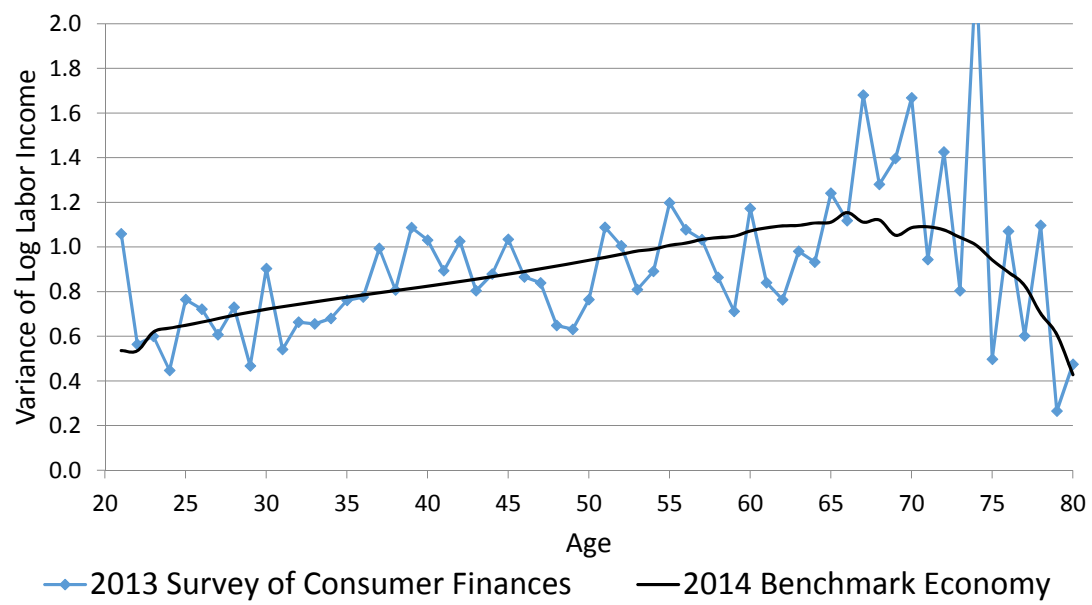

Sources: Author's calculations from the 2013 Survey of Consumer Finances (Federal Reserve Board, 2014).

corresponds to $\rho=0.95$ is obtained as

$$
\Pi_{i}=\left(\begin{array}{lllllll}
0.8591 & 0.1322 & 0.0085 & 0.0003 & 0.0000 & 0.0000 & 0.0000 \\
0.0220 & 0.8619 & 0.1103 & 0.0057 & 0.0001 & 0.0000 & 0.0000 \\
0.0006 & 0.0441 & 0.8636 & 0.0883 & 0.0034 & 0.0001 & 0.0000 \\
0.0000 & 0.0017 & 0.0662 & 0.8642 & 0.0662 & 0.0017 & 0.0000 \\
0.0000 & 0.0001 & 0.0034 & 0.0883 & 0.8636 & 0.0441 & 0.0006 \\
0.0000 & 0.0000 & 0.0001 & 0.0057 & 0.1103 & 0.8619 & 0.0220 \\
0.0000 & 0.0000 & 0.0000 & 0.0003 & 0.0085 & 0.1322 & 0.8591
\end{array}\right)
$$

for $i=21, \ldots, 79$.

\subsection{The Progressive Income Tax Function}

According to Table 4.B1 in Social Security Administration (2015), total covered earnings- the tax base of the HI payroll tax-are $\$ 7,147$ billion in 2013 , which are $42.6 \%$ of GDP and $72.2 \%$ of total labor income in the same year. In this paper, therefore, the ratio of taxable labor income to total labor income, $\eta$, is set at 0.722. The average household labor income for ages 21 to 64 is $\$ 65,766$ in the 2013 SCF (Federal Reserve Board, 2014). Because labor income per capita increased by 3.3\% in NIPA between 2013 and 2014, the average labor income is estimated at $\$ 67,936$ in 2014 . In the units employed in the model economy, the average labor income of households ages 21 to 64 is calculated as 0.6758 in the 2014 benchmark economy. 
Table 2: Fiscal Policy Parameter Values of the Aging-Population Baseline Economies

\begin{tabular}{|c|c|c|c|c|c|}
\hline Parameter & & Alt. 2 & Alt. 1 & Alt. 3 & Comment \\
\hline \multicolumn{6}{|l|}{ Model units } \\
\hline Taxable labor income ratio & $\eta$ & 0.7220 & 0.7220 & 0.7220 & Covered earnings / labor income \\
\hline Scale adjustment ${ }^{a}$ & & 139.196 & 139.250 & 139.109 & Average earnings $\$ 67,936$ \\
\hline \multicolumn{6}{|l|}{ Progressive income tax } \\
\hline Income tax: tax rate limit & $\varphi_{t}$ & 0.3745 & 0.3750 & 0.3740 & $T_{I, t} / Y_{t}=0.100$ \\
\hline : curvature & $\varphi_{1}$ & 0.7525 & 0.7525 & 0.7525 & \multirow{2}{*}{ Estimated by OLS } \\
\hline : scale & $\varphi_{2}$ & 0.7368 & 0.7370 & 0.7364 & \\
\hline$:_{\text {deduction/exemptions }}^{b}$ & $d$ & 0.1094 & 0.1093 & 0.1094 & $0.5 \times \$ 20,300+0.5 \times \$ 10,150$ \\
\hline \multicolumn{6}{|l|}{ Social Security system } \\
\hline S.S. payroll tax rate: OASI & $\tau_{O, t}$ & 0.1007 & 0.1007 & 0.1007 & Revenue $3.70 \%$ of GDP \\
\hline : DI & $\tau_{D, t}$ & 0.0171 & 0.0171 & 0.0172 & Revenue $0.63 \%$ of GDP \\
\hline$: \mathrm{HI}$ & $\tau_{H, t}$ & 0.0305 & 0.0305 & 0.0305 & Revenue $1.32 \%$ of GDP \\
\hline : HI surtax & $\tau_{H S, t}$ & 0.0090 & 0.0090 & 0.0090 & Current-law rate \\
\hline Maximum taxable earnings ${ }^{c}$ & $\vartheta_{\max }$ & 1.0507 & 1.0503 & 1.0513 & $(0.5 \times 1.5+0.5) \$ 117,000$ \\
\hline Repl. rate threshold: $0.90 \& 0.32^{c}$ & $\vartheta_{1}$ & 0.0879 & 0.0879 & 0.0880 & $(0.5 \times 1.5+0.5) \$ 816 \times 12$ \\
\hline$: 0.32 \& 0.15^{c}$ & $\vartheta_{2}$ & 0.5299 & 0.5297 & 0.5302 & $(0.5 \times 1.5+0.5) \$ 4,917 \times 12$ \\
\hline HI surtax threshold ${ }^{b}$ & $\vartheta_{3}$ & 1.6164 & 1.6158 & 1.6174 & $0.5 \times \$ 250,000+0.5 \times \$ 200,000$ \\
\hline Benefit adjustment factor: OASI & $\psi_{O, t}$ & 1.5776 & 1.5760 & 1.5788 & Benefits $4.01 \%$ of GDP \\
\hline : DI & $\psi_{D, t}$ & 0.0100 & 0.0100 & 0.0100 & Benefits $0.84 \%$ of GDP \\
\hline$: \mathrm{HI}$ & $\psi_{H, t}$ & 0.0777 & 0.0777 & 0.0778 & Benefits $1.56 \%$ of GDP \\
\hline \multicolumn{6}{|l|}{ Other policy variables } \\
\hline Government's consumption per capita & & 0.0342 & 0.0342 & 0.0343 & Calculated as a residual \\
\hline Lump-sum transfers per capita & $t r_{L S, t}$ & 0.0727 & 0.0727 & 0.0728 & Non-SS transfers $7.44 \%$ of GDP \\
\hline Consumption tax rate & $\tau_{C, t}$ & 0.0246 & 0.0246 & 0.0246 & $T_{C, t} / Y_{t}=0.016$ \\
\hline Government's net worth per capita & $w_{G, t}$ & 0.0293 & 0.0293 & 0.0293 & $W_{G, t} / Y_{t}=0.03$ \\
\hline
\end{tabular}

Note: This baseline calibration uses the population projections alternative 2 (intermediate scenario), alternative 1 (low-cost scenario), and alternative 3 (high-cost scenario) for Social Security Administration (2014). ${ }^{a}$ A unit in the model economy corresponds to $\$ 139,196(\$ 139,250, \$ 139,109)$ in 2014 growth-adjusted dollars. ${ }^{b} 50 \%$ of all households are assumed to be married, and the other $50 \%$ of households are single. ${ }^{c}$ Each married household is assumed to have 1.5 full-time equivalent workers.

Under this assumption, one model unit for an individual household corresponds to $\$ 67,936 /(0.6758 \times$ $0.722)=\$ 139,216$ in 2014 growth-adjusted U.S. dollars. This scale factor converts some of the policy variables under the current law into the model parameters.

The individual income tax function is one of Gouveia and Strauss (1994),

$$
\tau_{I, t}\left(w_{t} e h, r_{t} a, \operatorname{tr}_{S S, t}(i, b)\right)=\tilde{\tau}_{I, t}(y)=\varphi_{t}\left[y-\left(y^{-\varphi_{1}}+\varphi_{2}\right)^{-1 / \varphi_{1}}\right]
$$

where

$$
y=\max \left\{r_{t} a+\eta w_{t} e h+r_{t} a+\zeta\left(\eta w_{t} e h+r_{t} a, t r_{S S, t}(i, b)\right)-d, 0\right\}
$$


Figure 5: The Marginal Labor Income Tax Rate Schedule of Households

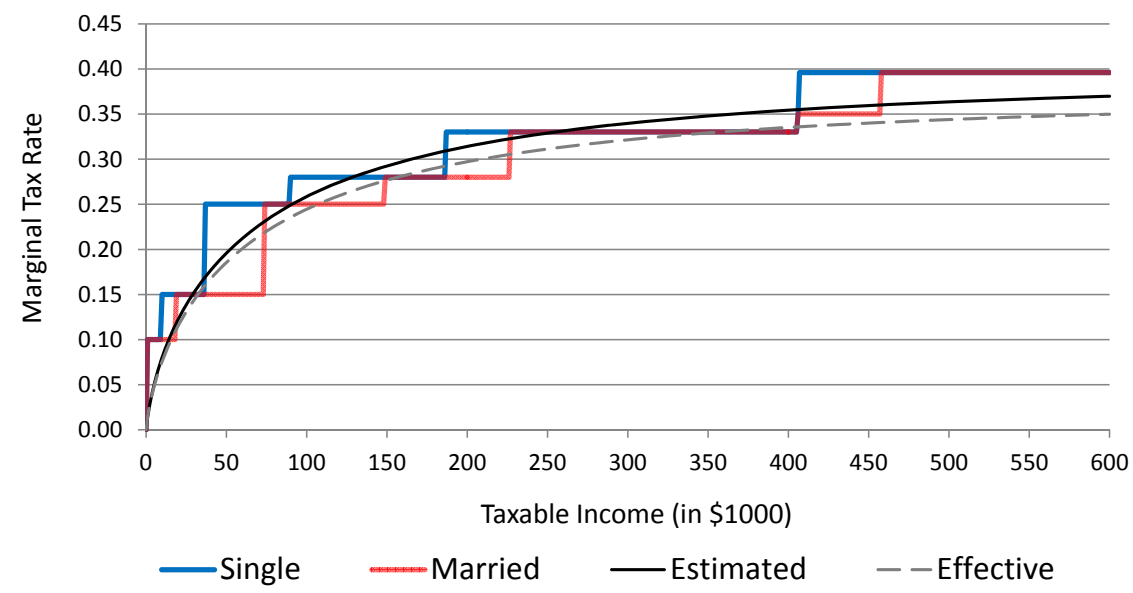

Sources: Author's calculations from the Internal Revenue Service (2015).

is the household's taxable income with constant deductions and exemptions $d$, and $\zeta(\cdot)$ calculates the taxable portion of Social Security benefits 24

The first parameter, $\varphi_{t}$, of the Gouveia-Strauss function shows the limit of the effective marginal income tax rate as taxable income goes to infinity. This paper initially sets this first parameter at 0.396 or $39.6 \%$, which is the marginal income tax rate for the highest tax bracket. Then, this paper estimates the other two parameters, $\varphi_{1}$ and $\varphi_{2}$, by OLS with the 2014 statutory marginal tax rate schedule, assuming 50\% of households are married filing jointly and $50 \%$ of households are single. The second parameter, $\varphi_{1}=0.7525$, shows the curvature of the tax function; and the third parameter, $\varphi_{2}=0.7368$, is used to adjust the scale of the tax function 25 The federal income tax revenue, the sum of the individual income tax revenue and the corporate income tax revenue, is $10.0 \%$ as a share of GDP in fiscal year 2014. So, this paper finally adjusts the first parameter, $\varphi_{t}$, to 0.3745 so that the income tax revenue as a share of GDP is $10.0 \%$ in the 2014 benchmark economy. Figure 5 shows the marginal income tax rates under the current law and estimated by using the Gouveia-Strauss function.

In 2014 , the standard deduction is $\$ 6,200$ for a single household and $\$ 12,400$ for a married household filing return jointly. In the same year, the exemption is $\$ 3,950$ per person. When $50 \%$ of households are assumed to be married and 50\% are assumed to be single, the sum of the deduction and exemptions is, on average, $0.5(12,400+7,900)+0.5(6,200+3,950)=15,225$ in 2014 growth-adjusted dollars. The

\footnotetext{
${ }^{24}$ For the taxation on Social Security benefits, see Tables 2.A.31-32 in Social Security Administration (2014).

${ }^{25}$ This paper initially estimates the third parameter, $\varphi_{2}$, as 0.017958 by using labor income in thousands of dollars, then the paper rescales the Gouveia-Strauss tax function to model units as $\varphi_{2}=0.017958 \times 139.196^{\varphi_{1}}=0.7368$, where 139.196 is a scale parameter explained above.
} 
parameter, $d$, is set at $15,225 / 139,196=0.1094$ by converting the above number into model units.

\subsection{The Social Security System}

The Social Security OASDHI payroll tax function is

$$
\tau_{P, t}\left(w_{t} e h\right)=\left(\tau_{O, t}+\tau_{D, t}\right) \min \left(\eta \cdot w_{t} e h, \vartheta_{\max }\right)+\tau_{H, t} \eta \cdot w_{t} e h+\tau_{H S, t} \max \left(\eta \cdot w_{t} e h-\vartheta_{3}, 0\right),
$$

where $\tau_{O, t}$ is the flat Old-Age and Survivors Insurance (OASI) tax rate, $\tau_{D, t}$ is the flat Disability Insurance (DI) tax rate, $\tau_{H, t}$ is a flat Hospital Insurance (HI, Medicare Part A) tax rate, and $\tau_{H S, t}$ is a flat HI surtax rate. These payroll tax rates include the portion of taxes paid by employers. The payroll tax revenues for the OASI, DI, and HI programs are 3.70\%, 0.63\%, and 1.32\%, respectively, as a share of GDP in 2013, according to Tables 4.A1, 4.A2, and 8.A1 in Social Security Administration (2014). This paper sets $\tau_{H S, t}$ at 0.009 , which is the statutory HI surtax rate. Then, this paper sets $\tau_{O, t}, \tau_{D, t}$, and $\tau_{H, t}$ at $0.1007,0.0171$, and 0.0305, respectively, so that the payroll tax revenues for the OASI, DI, and HI programs as a share of GDP in the 2014 benchmark economy are consistent with the data in 2013 26

The maximum taxable earnings per worker for the OASDI payroll tax were $\$ 117,000$ in 2014 (SSA, 2015). This paper assumes that 50\% of households are married households, and each of those household has 1.5 full-time equivalent workers. Thus, this paper sets the maximum taxable earnings, $\vartheta_{\max }$, as the weighted average of 1.5 (married households) and 1.0 (single households). In the 2014 benchmark economy, the maximum taxable earnings for a household are at 1.0507 in model units, which correspond to $(0.5 \times$ $1.5+0.5 \times 1.0) \$ 117,000=\$ 146,250$ per household in 2014 . The threshold for the HI surtax is currently $\$ 250,000$ for a married household and $\$ 200,000$ for a single household. In the benchmark economy, the surtax threshold, $\vartheta_{3}$, is at 1.6164 in model units, which corresponds to $0.5 \times \$ 250,000+0.5 \times \$ 200,000=$ $\$ 225,000$ per household in 2014.

The Social Security OASDHI benefit function is

$$
\begin{aligned}
\operatorname{tr}_{S S, t}(i, b)=\mathbf{1}_{\left\{i \geq I_{\tilde{R}}\right\}} \psi_{O, t} \frac{1}{(1+\mu)^{i-60}}\left\{0.90 \min \left(b, \vartheta_{1}\right)+0.32 \max \left[\min \left(b, \vartheta_{2}\right)-\vartheta_{1}, 0\right]\right. \\
\left.+0.15 \max \left(b-\vartheta_{2}, 0\right)\right\}+\mathbf{1}_{\left\{i<I_{\tilde{R}}\right\}} \psi_{D, t} \cdot \kappa_{D, i}+\mathbf{1}_{\left\{i \geq I_{R}\right\}} \psi_{H, t} \cdot \kappa_{H, i},
\end{aligned}
$$

\footnotetext{
${ }^{26}$ When labor income is below the maximum taxable earnings, the statutory OASI tax rate is $10.6 \%$, including $5.3 \%$ paid by employers. The effective OASI tax rate is, therefore, $0.106 / 1.053=0.1007$ or $10.07 \%$, which is almost equal to the effective OASI tax rate in the 2014 benchmark economy. The statutory DI and HI tax rates are $1.8 \%$ and $2.9 \%$, respectively. The effective $\mathrm{HI}$ tax rate in the benchmark economy is higher than the statutory rate because the model cannot capture the revenue from the HI surtax for high-income workers perfectly.
} 
Figure 6: The Ratio of the DI Beneficiary Rate by Age to the Average DI Beneficiary Rate (average = 1.0)

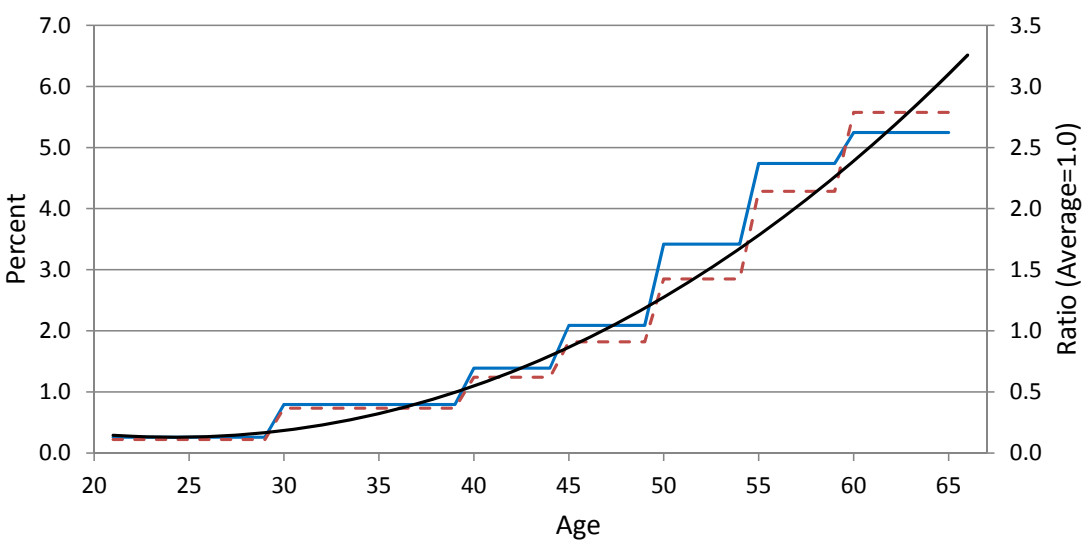

— Share in Total DI Beneficiaries _ - - DI Rate by Age/Average DI Rate _ — DI Rate by Age/Average DI Rate (Est.)

Sources: Author's calculations from the Social Security Administration (2015).

where $I_{\tilde{R}}$ is the full retirement age and set between ages 65 and 67 in two-month increments, depending on the household's birth year ${ }^{27} I_{R}$ is the Medicare eligibility age (age 65); $\vartheta_{1}$ and $\vartheta_{2}$ are the thresholds for the three replacement rate brackets, $90 \%, 32 \%$, and $15 \%$, that calculate the OASI benefit from the average historical earnings; $\psi_{O, t}$ is the adjustment factor of the OASI benefits; $\kappa_{D, i}$ is the ratio of the DI eligibility rate for age $i$ to the average DI eligibility rate; $\psi_{D, t}$ is the average DI benefit in year $t ; \kappa_{H, i}$ is the ratio of the average $\mathrm{HI}$ benefit (cost) for age $i$ to the average $\mathrm{HI}$ benefit for all beneficiaries; and $\psi_{H, t}$ is the average HI benefit in year $t$.

The current U.S. Social Security system determines the thresholds to calculate primary insurance amounts for each age cohort when a worker reaches age 62. This paper fixes the growth-adjusted thresholds at the same level for all age cohorts and adjusts the PIA later by using the long-term productivity growth rate and years after age 60. Thus, the model simply uses the thresholds for the age 62 cohort in 2014 after scale adjustment ${ }^{28}$ Figure 6 shows the share of DI beneficiaries by age and the ratio of the DI eligibility rate by age to the overall average DI eligibility rate (the likelihood of receiving DI benefits by age). This paper estimates the latter, $\kappa_{D, i}$, by OLS to the distribution of DI benefits by age. Figure 7 shows the average cost of HI benefits by age in 2011, estimated by Numan, Cubanski, and Damico (2015). This paper also estimates the average HI benefit by age by OLS and calculates $\kappa_{H, i}$ as the ratio of the average HI benefit by age to the

\footnotetext{
${ }^{27}$ As explained in Section 2, households are assumed to start claiming their OASI benefits at their full retirement age (FRA), $I_{\tilde{R}}$, although they can continue working if they like.

${ }^{28}$ Under the current system, AIMEs for those ages 60 and older are not wage-indexed but price-indexed, and the bracket thresholds are also price-indexed for each age cohort. To simplify the computation in the growth economy, the model first assumes all of the above variables are wage-indexed. Then, the model converts the Social Security benefits to be price-indexed by dividing the benefits by $(1+\mu)^{i-60}$.
} 
Figure 7: The Average Cost of HI Benefits by Age in 2011 (in U.S. dollars)

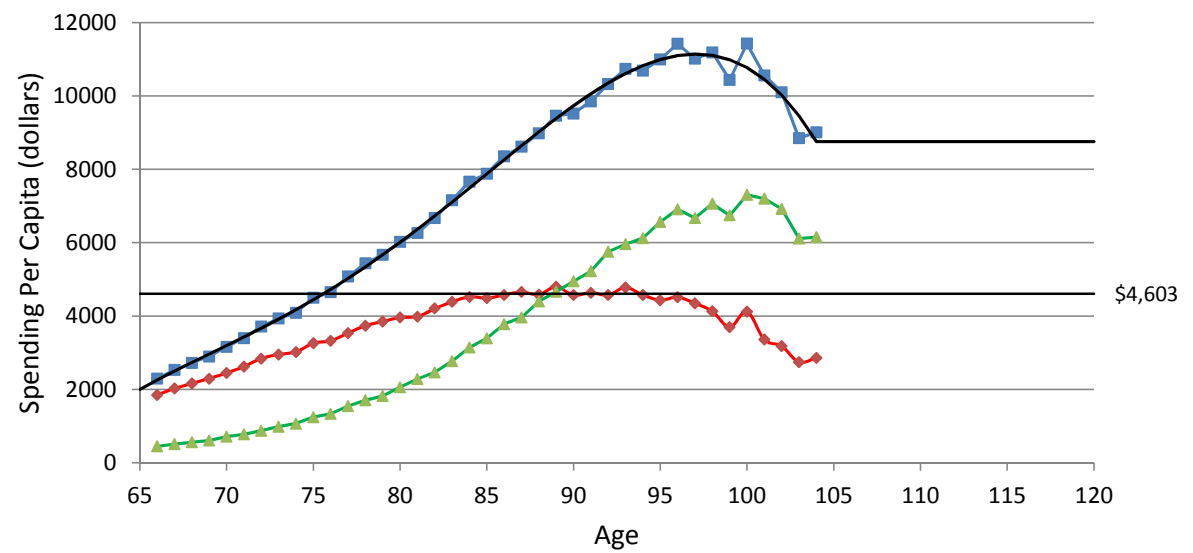

$\rightarrow$-Mecicare Part A $\rightarrow-$ Hospital Inpatient $\rightarrow-S N F$, home health, hospice —Medicare Part A (Est.) —Wgt'd Average

Source: Numan, Cubanski, and Damico (2015).

overall average $\mathrm{HI}$ benefit.

The benefit expenditures for the OASI, DI, and HI programs are $4.01 \%, 0.84 \%$, and $1.56 \%$, respectively, as a share of GDP in 2013, according to Tables 4.A1, 4.A2, and 8.A1 in Social Security Administration (2014). This paper, therfore, sets $\psi_{O, t}, \psi_{D, t}$, and $\psi_{H, t}$ at $1.5779,0.0104$, and 0.0846 , respectively, so that the benefit expenditures for the OASI, DI, and HI programs as a share of GDP in the 2014 benchmark economy are consistent with the data in 20132

\subsection{The Other Policy Variables}

The government's (beginning-of-year) debt held by the public is $70.9 \%$ as a share of GDP in 2014, according to the Treasury Department and NIPA. The government's (beginning-of-year) capital stock is $74.0 \%$ as a share of GDP in the same year, according to NIPA. This paper, for simplicity, assumes that the government's capital stock and debt held by the public cancel out to each other, and the model uses the government's net worth per household, $w_{G, t}$, as one of its policy variables. In the 2014 benchmark economy, the government's (beginning-of-year) net worth is assumed to be $3.0 \%$ of GDP.

The government's non-Social Security (OASDHI) transfer spending is 7.44\% as a share of GDP in 2013, according to NIPA and Social Security Administration (2015). In the 2014 benchmark economy, lump-sum transfers per household, $\operatorname{tr} L S, t$, is assumed to be $7.44 \%$ of GDP. The government's consumption spending

\footnotetext{
${ }^{29}$ There is no disability risk or health risk in the model economy, for simplicity. DI benefits and HI benefits are age dependent but uniformly distributed for each age. So, the model implicitly assumes that the government transfers the actuarially-fair insurance premiums for DI and HI, rather than realized insurance benefits, to those households.
} 
is 5.7\% as a share of GDP in 2013, according to NIPA. In the 2014 benchmark economy, however, it is calculated as a residual for each year so that the government's net worth (capital stock net of debt) per household stays at the same level after the productivity-growth adjustment. So, it is assumed to be 3.5\% of GDP in the 2014 benchmark economy, which is smaller than $5.7 \%$ in NIPA ${ }^{30}$ The rate of the national consumption tax, which approximates the excise tax and other taxes, is set at $\tau_{C, t}=0.0246$ or $2.46 \%$ so that the consumption tax revenue is $1.6 \%$ of GDP in the 2014 benchmark economy.

\section{The Aging Baseline Economies}

This section shows the aging-population baseline economies with SSA's population projections Alternative 2 (intermediate scenario) as well as Alternatives 1 (low-cost scenario) and 3 (high-cost scenario). These baseline economies assume that the government cut its consumption spending to keep its growthadjusted net worth per household at the same level. In this paper, therefore, these economies do not consider any feedbacks effects of the government's policy changes on individual behaviors and the overall economy. This section also explains the fiscal gaps in the three aging-population baseline economies. The fiscal gap shows how much the government will have to reduce its primary deficits in the future, relative to the deficits under the current-law fiscal policies, in order to make the government budget sustainable.

\subsection{The Aging-Population Baseline Relative to the 2014 Benchmark Economy}

Figure 8 shows the aging-population baseline economy for the years from 1980 to 2200 . Each panel of the figure shows the changes from the 2014 benchmark economy, which year is indicated by the vertical line in each panel. In other words, the horizontal line at 0.0 indicates the balanced growth path that goes through the 2014 economy in the absence of the aging population; and each panel shows the effect of the aging population (demographic changes) under the current-law (2014 benchmark) fiscal policies.

According to the model, if fiscal policies had been unchanged at the 2014 benchmark levels, labor supply per capita would have increased since the mid-1980s and peaked around 2006-2007. The years from 1980 to 2006 coincide with the period when the baby boomers had a central role in the U.S. labor market. The baby boomers started retiring in 2008, and the proportion of working-age households and labor supply per capita would have declined since then and will continue declining over time ${ }^{31}$ This is the direct effect of the

\footnotetext{
${ }^{30}$ In other words, there is a fiscal gap as large as $2.2 \%$ of GDP in 2014 before assuming any demographic changes in the future. For simplicity, however, this paper only considers the fiscal gap caused by the projected aging population, which is around $3.0 \%$ of GDP under the population projection alternative 2. This existing fiscal gap, $2.2 \%$, is relatively large partly because the model assumes that the government's capital stock and its debt change in parallel so that its net worth stays at the same level.

${ }^{31}$ In this paper, percent changes in labor supply per capita are equal to percent changes in labor supply per household but not
} 
Figure 8: The Aging-Population Baseline Economy Relative to the 2014 Benchmark Economy
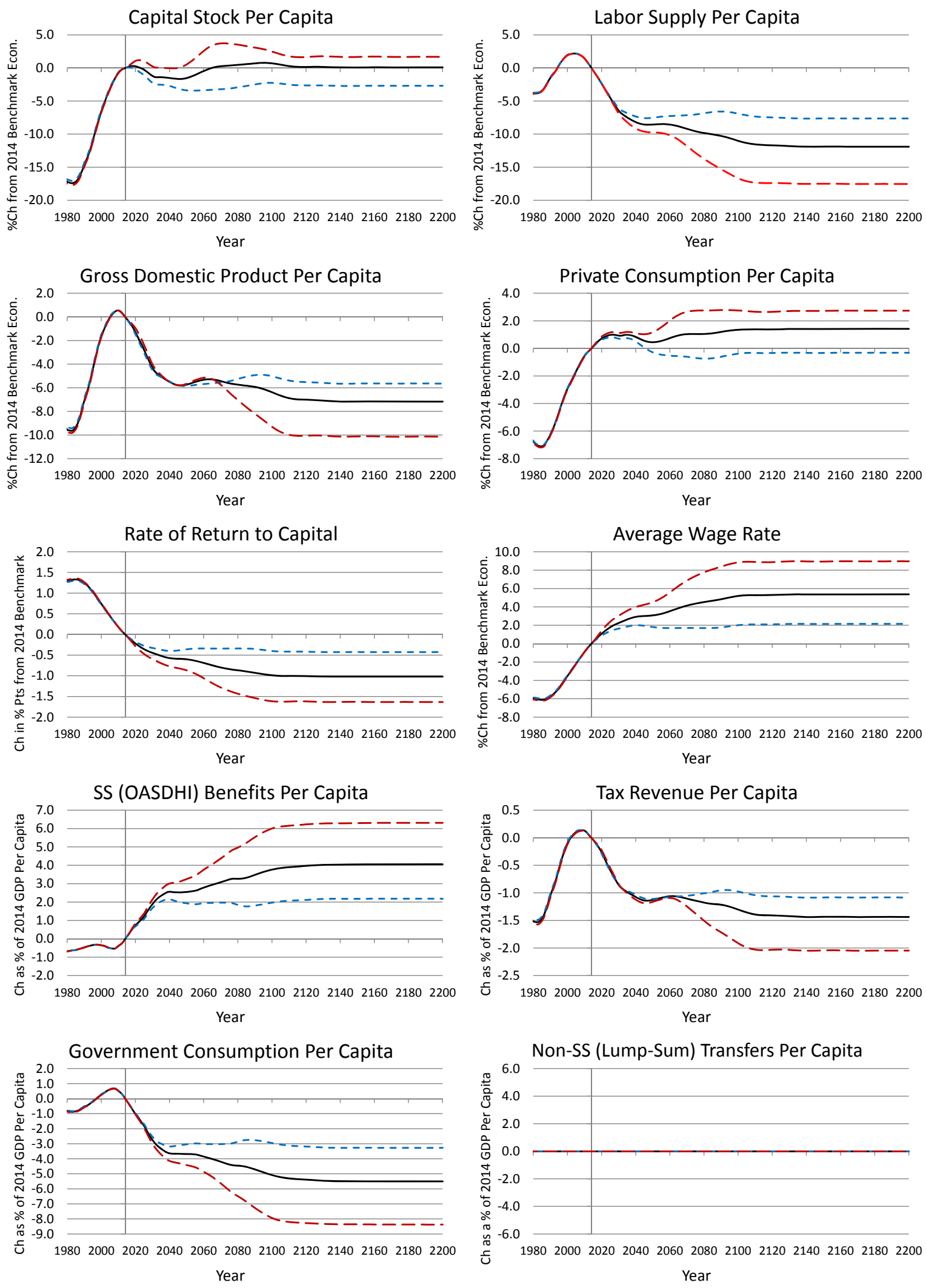

—Alternative 2 (Intermediate) - - -Alternative 1 (Low-Cost) - -Alternative 3 (High-Cost) 
aging population on the U.S. economy. Labor supply per capita will be $8.1 \%$ (7.2\%, 9.0\%) lower in 2039 and $11.9 \%(7.6 \%, 17.5 \%)$ lower in the long run under Alternative 2 (Alternative 1, Alternative 3 ) relative to the economy without the aging population (the 2014 benchmark economy).

It is, in general, difficult to predict the economy's capital stock, because it depends not only on the households' saving decision but also on the government's debt in the future. In this paper, however, the government's net worth per capita is kept constant, after the productivity-growth adjustment, at the 2014 benchmark level. If the government cuts its consumption spending-in other words, if no additional budgetary feedbacks to the household's budget are considered-capital stock per capita will be $1.5 \%$ (2.7\%, $0.0 \%)$ lower in 2039 and $0.1 \%(-2.7 \%, 1.7 \%)$ higher in the long run relative to the 2014 benchmark economy. The capital stock will increase in the long run, under Alternatives 2 and 3, because the households will have to accumulate larger wealth for their retirement if life expectancy is higher and the government's fiscal policies are not changed.

In the aging baseline economy, other things being equal, GDP per capita would have increased since the early-1980s and peaked around 2010; then, it will likely decrease over time. The potential GDP per capita growth rate would have been higher than the long-run productivity growth rate until 2010 and will be lower than the long-run rate,at least, until the mid-2040s, because of the change in the share of the working-age households. GDP per capita will be 5.4\% (5.4\%, 5.4\%) lower in 2039 and $7.2 \%(5.6 \%, 10.1 \%)$ lower in the long run with the aging population if the budgetary costs of aging are financed by cuts in government consumption.

Because of the decrease in labor supply per capita and GDP per capita, the disposable income of households will also decrease, on average, by $2.0 \%(2.2 \%, 1.8 \%)$ in 2039 and $2.3 \%(2.4 \%, 2.9 \%)$ in the long run. However, the private saving rate will also decrease, on average, by $2.6(2.5,2.7)$ percentage points in 2039 and $3.4(1.9,5.2)$ percentage points in the long run. In the aging baseline economy, capital stock per capita will increase slightly in the long run, although the household's average saving rate falls. This is because the the private saving rate is above its steady-state level in the 2014 benchmark economy, and it gradually decreases to the steady-state level in the long run. Private consumption per capita, therefore, will increase modestly by $0.9 \%(0.6 \%, 1.1 \%)$ in 2039 and $1.4 \%(-0.3 \%, 2.7 \%)$ in the long run.

Though capital stock per capita will stay around the 2014 benchmark level after productivity-growth adjustment, labor supply per capita will decrease significantly. Thus, the rate of return to capital will fall gradually by $0.56 \%(0.39 \%, 0.76 \%)$ in 2039 and $1.02 \%(0.43 \%, 1.63 \%)$ in the long run, and the average wage rate will increase by $2.9 \%(2.0 \%, 3.9 \%)$ in 2039 and $5.4 \%(2.2 \%, 9.0 \%)$ in the long run.

equal to percent changes in labor supply per worker or working-age household. Labor supply per working-age household will increase as households expect to live longer in the aging baseline economy. 
The aging population will significantly affect the government budget in the future. If the government's fiscal policy is unchanged, except for the size of the government consumption that, by assumption, does not affect the households' behavior, the government's Social Security (OASDHI) benefit expenditure will grow rapidly by $2.5 \%(2.2 \%, 3.0 \%)$ as a share of GDP in 2039 and by $4.1 \%(2.2 \%, 6.3 \%)$ as a share of GDP in the long run. To make things worse, the government's revenue from taxes (the income tax, the payroll tax, and the consumption tax) will decrease by $1.1 \%(1.0 \%, 1.1 \%)$ as a share of GDP in 2039 and $1.4 \%(1.1 \%$, $2.0 \%$ ) as a share of GDP in the long run.

In the aging-population baseline economy, accordingly, the government will have to decrease its consumption spending as a share of GDP by $3.6(3.2,4.1)$ percentage points in 2039 and by $5.5(3.3,8.4)$ percentage points in the long run. It is obviously unrealistic to assume that the government will be able to cut its consumption by these percentage points, as the government's consumption is $5.7 \%$ of GDP in 2013 and $3.5 \%$ of GDP in the 2014 benchmark economy. In Section 5, therefore, this paper introduces alternative fiscal policy changes - raising taxes or cutting Social Security benefits— to the aging-population baseline economy and analyzes the overall effect of the aging population on the economy.

\subsection{The Fiscal Gaps of the Current Government Policies}

The fiscal gap of the government's current-law fiscal policies is the present discount sum of the government's primary deficits from the present year through the infinite future. Economists often show the fiscal gap as a percentage of the present discount sum of GDP over the same period. Table 3 shows the fiscal gaps - total and by the government's program—under SSA's population projections Alternative 2, Alternative 1, and Alternative 3. When the model uses the realized real interest rate, $r_{t}$, over the transition path, the total fiscal gap in the aging-population baseline economy is $2.94 \%(2.31 \%, 3.80 \%)$ as a share of GDP under Alternative 2 (Alternative 1, Alternative 3). This number 2.94\% indicates that the government will have to reduce its primary deficits by $2.94 \%$ of GDP every year from the present year (2014) through the infinite future in order to make the policy sustainable ${ }^{32}$ The fiscal gap of the Social Security (OASDHI) programs is $3.14 \%(2.55 \%, 3.92 \%)$ as a share of GDP, and the fiscal gap of the rest of the government budget is $-0.20 \%$ (-0.24\%. $-0.12 \%)$. In this paper, the fiscal gap of the rest of the government is negative because the model constructs the government's fiscal policies in the 2014 benchmark economy to be sustainable in the absence of the aging population.

In the aging-population baseline economies, when the government's growth-adjusted consumption per

\footnotetext{
${ }^{32}$ In 2014, the government's income tax revenue is about $10.0 \%$ of GDP, and the Social Security payroll tax revenue is $5.65 \%$ of GDP. Cutting primary deficits every year by $2.94 \%$ of GDP is not an easy policy change for the government, and it will generate significant effects on individual households and the overall economy, which will be discussed in Section 5.
} 
Table 3: The Fiscal Gap in the Aging-Population Baseline Economies

\begin{tabular}{|c|c|c|c|c|c|c|c|}
\hline & \multirow[t]{2}{*}{ GDP } & \multirow[t]{2}{*}{ Total } & \multicolumn{4}{|c|}{ Social Security } & \multirow{2}{*}{$\begin{array}{l}\text { Rest of the } \\
\text { government }\end{array}$} \\
\hline & & & Total & OASI & DI & HI & \\
\hline \multicolumn{8}{|c|}{ Alternative 2 (intermediate) } \\
\hline \multicolumn{8}{|c|}{ Discount rate $=r_{t}$} \\
\hline Present discount value & 1457.5 & 42.88 & 45.82 & 27.13 & 2.98 & 15.71 & -2.94 \\
\hline Fiscal gap (\%GDP) & & 2.94 & 3.14 & 1.86 & 0.20 & 1.08 & -0.20 \\
\hline \multicolumn{8}{|l|}{ Discount rate $=6.0 \%$} \\
\hline Present discount value & 1278.9 & 34.57 & 37.65 & 22.22 & 2.63 & 12.80 & -3.08 \\
\hline Fiscal gap (\%GDP) & & 2.70 & 2.94 & 1.74 & 0.21 & 1.00 & -0.24 \\
\hline \multicolumn{8}{|l|}{ Alternative 1 (low-cost) } \\
\hline \multicolumn{8}{|l|}{ Discount rate $=r_{t}$} \\
\hline Present discount value & 1428.0 & 32.99 & 36.44 & 21.16 & 2.91 & 12.37 & -3.45 \\
\hline Fiscal gap (\%GDP) & & 2.31 & 2.55 & 1.48 & 0.20 & 0.87 & -0.24 \\
\hline \multicolumn{8}{|l|}{ Discount rate $=6.0 \%$} \\
\hline Present discount value & 1319.0 & 29.58 & 32.96 & 19.14 & 2.70 & 11.13 & -3.39 \\
\hline Fiscal gap (\%GDP) & & 2.24 & 2.50 & 1.45 & 0.20 & 0.84 & -0.26 \\
\hline \multicolumn{8}{|l|}{ Alternative 3 (high-cost) } \\
\hline \multicolumn{8}{|l|}{ Discount rate $=r_{t}$} \\
\hline Present discount value & 1491.3 & 56.66 & 58.48 & 35.08 & 3.07 & 20.33 & -1.82 \\
\hline Fiscal gap (\%GDP) & & 3.80 & 3.92 & 2.35 & 0.21 & 1.36 & -0.12 \\
\hline \multicolumn{8}{|l|}{ Discount rate $=6.0 \%$} \\
\hline Present discount value & 1240.0 & 39.76 & 42.39 & 25.28 & 2.57 & 14.54 & -2.63 \\
\hline Fiscal gap (\%GDP) & & 3.21 & 3.42 & 2.04 & 0.21 & 1.17 & -0.21 \\
\hline
\end{tabular}

Note: The present discount values are in model units as of the beginning of 2014.

household is fixed at the 2014 level, the primary deficits as a share of GDP will increase over time. Therefore, the fiscal gap measure is sensitive to the choice of the discount rate to calculate the present discount values. If the discount rate is fixed at the real interest rate, $6.0 \%$, in the 2014 benchmark economy, the fiscal gap will be smaller. The total fiscal gap in the aging-population baseline economy is $2.70 \%(2.24 \%, 3.21 \%)$ as a share of GDP under Alternative 2 (Alternative 1, Alternative 3).

\section{Financing the Aging Population}

Section 4 calibrates the model to the U.S. economy with the aging population. The projected aging population will affect individual households through the changes in their mortality rates and factor prices in the economy; the overall economy (per household) through the decrease in the share of the working-age households as well as the population growth rate; and the government budget through the decrease in tax revenue and the increase in Social Security benefit spending. In the aging-population baseline economy, however, the government is assumed to balance its budget, thus stabilize the debt-to-GDP ratio, by cutting 
Figure 9: The Assumption for the Policy Experiments: Recreating the Fiscal Gap

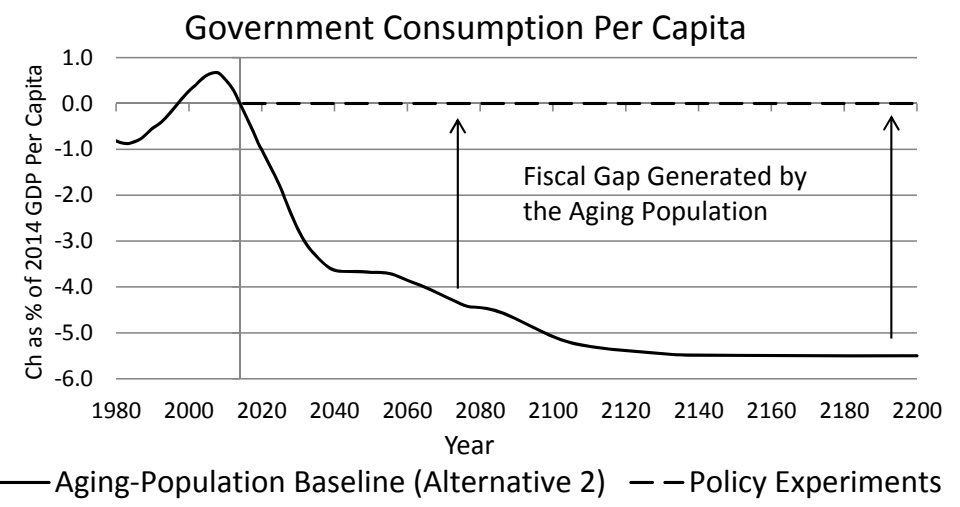

government consumption without affecting the rest of the economy. In this model economy, the government consumption is not in the household's utility function or its budget constraint. Therefore, the aging baseline economy shows the effect of the demographic changes projected in the United States without considering its budgetary feedback (the effect from the government's future policy changes).

This section, more realistically, assumes that the government keeps its consumption spending per household between 2014 and 2200 at the 2014 benchmark level instead of cutting it to balance the budget (See Figure 9p. This assumption creates a fiscal imbalance each year in 2014-2200 or, equivalently, creates a fiscal gap in the current fiscal policy. The government then introduces an alternative fiscal policy to close this fiscal gap and make the fiscal policy sustainable. The alternative fiscal policies introduced in this section are

- increasing lump-sum taxes uniformly,

- raising progressive income tax rates proportionally,

- raising the flat consumption tax rate,

- cutting Social Security (OASI, DI, HI) benefits proportionally, and

- raising Social Security (OASI, DI, HI) payroll tax rates proportionally,

- cutting S.S. benefits and raising payroll tax rates proportionally,

to keep the government's net worth per household at the 2014 level after the growth adjustment ${ }^{33}$ Under

\footnotetext{
${ }^{33}$ Increasing lump-sum taxes uniformly is equivalent to decreasing lump-sum transfers uniformly in the model economy. This is the least redistributive policy change, whereas raising progressive income tax rates proportionally is the most redistributive policy change, among the above six policy changes.
} 
each of the above policy assumptions, this paper solves the model with the aging population for an equilibrium transition path in 2014-2200. Thus, each policy experiment shows the effect of the aging population on the economy with the additional budgetary feedback through a specific policy change to close the fiscal gap.

\subsection{Increasing the Lump-Sum Tax, Income Tax, or Consumption Tax}

This section introduces three broad fiscal policy changes-increasing lump-sum taxes uniformly, raising marginal income tax rates proportionally, and raising the flat consumption tax rate-one by one, to show the effects of tax increase policies. Figure 10 shows the macroeconomic and budgetary effects of these policy changes, and Figure 11 shows the welfare effect of the same policy changes. For easier comparison, the figures also include the results in the aging-population baseline economy, where the government cuts its consumption each year to close the fiscal gap caused by the demographic changes.

\subsubsection{Increasing Lump-Sum Taxes Uniformly}

Blue dashed lines in Figure 10 show the results when the government closes the fiscal gap by increasing lump-sum taxes uniformly instead of cutting its consumption as in the aging baseline economy. Increasing lump-sum taxes uniformly will reduce the household's consumption, especially when their income is low or they are retired. Therefore, relative to the aging baseline economy, the households will work longer and increase their precautionary and life cycle savings. Relative to the 2014 benchmark economy, labor supply per capita will decrease by $6.4 \%$ in 2039 and $9.5 \%$ in the long run $(8.1 \%$ and $11.9 \%$, respectively, in the aging baseline). Capital stock per capita will increase by $3.3 \%$ in 2039 and $4.6 \%$ in the long run (-1.5\% and $0.1 \%$, respectively, in the aging baseline). Accordingly, GDP per capita will decrease by $2.5 \%$ in 2039 and $4.0 \%$ in the long run $(5.4 \%$ and $7.2 \%$, respectively, in the aging baseline). Thus, increasing lump-sum taxes uniformly attenuates the negative effect of the aging population on the overall economy by forcing households to work longer and save more.

To close the fiscal gap, under this assumption, the government will have to increase lump-sum taxes by $3.3 \%$ as a share of the benchmark GDP in 2039 and 5.2\% in the long run. This policy change will reduce the household's disposable income and their consumption. Relative to the 2014 benchmark economy, private consumption per capita will decrease by $2.0 \%$ in 2039 and $4.1 \%$ in the long run (increase by $0.9 \%$ and $1.4 \%$, respectively, in the aging baseline).

Blue dashed lines in Figure 11 show the welfare changes by age cohort after the policy change in 2014. The horizontal axis shows the age of households when the policy is changed (in 2014), and the vertical axis 
Figure 10: The Macroeconomic and Budgetary Effects of the Aging Population (Changes from the 2014 Benchmark Economy)
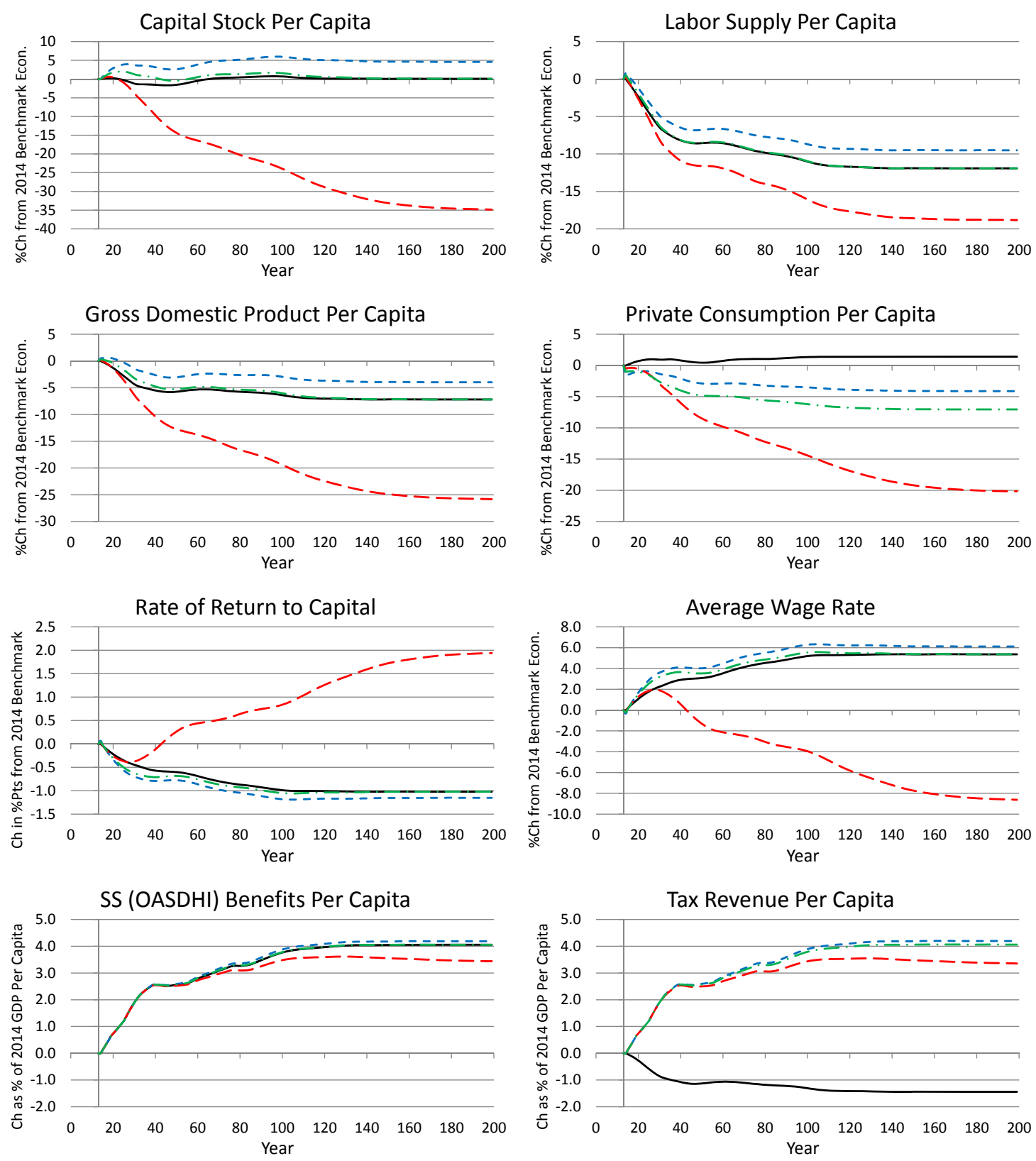

Gov't Cons. \& Lump-Sum Taxes×(-1) P.C.
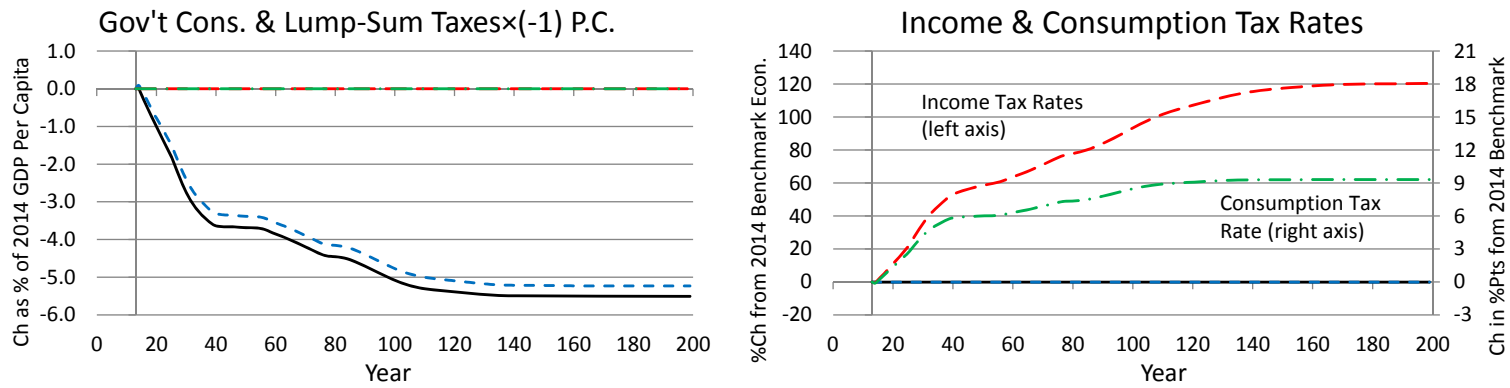

—Cutting Gov't Consumption - - Raising Income Tax Rates

\section{- - Increasing Lump-Sum Taxes \\ - - Raising Consumption Tax Rate}


Figure 11: The Welfare Effects of the Aging Population (Changes from the Aging-Population Baseline Economy)
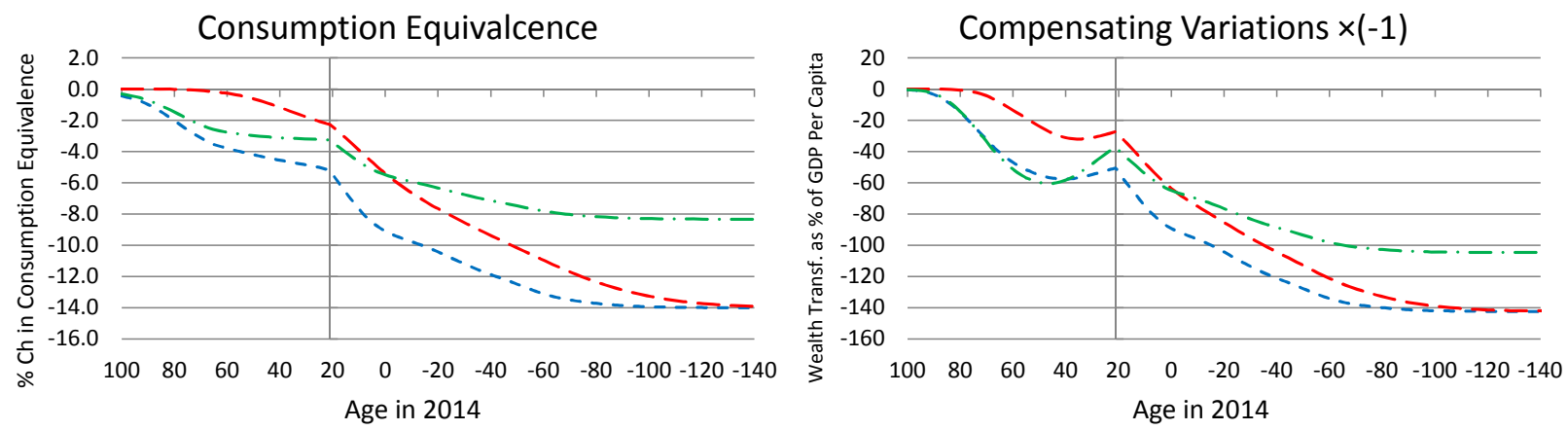

- - - Increasing Lump-Sum Taxes _ - - Raising Income Tax Rates _ - - Raising Consumption Tax Rate

shows the welfare gains (losses if negative) relative to the aging baseline economy. The additional vertical line is set at age 21. The left of this line shows the current households in 2014 and the right of the vertical line shows the future generations. The first graph shows the welfare changes in the consumption equivalence measure described in Section 2.5.1, and the second graph shows the welfare changes in the compensating variation measure described in 2.5.2 ${ }^{34}$ Not surprisingly, cutting transfer spending will decrease the household's average consumption and leisure hours, thus the policy change will make almost all age cohorts, on average, worse off. What might be surprising is that, for almost all age cohorts, their welfare loss is the biggest (worst) of the three alternative policy changes (tax increases) discussed in this section, although its effect on the overall economy is the best of the three policy changes. This is because increasing lump-sum taxes uniformly hurts low-income households most.

\subsubsection{Raising Marginal Income Tax Rates Proportionally}

Red long-dashed lines in Figure 10 show the results when the government closes the fiscal gap by raising marginal income tax rates proportionally instead of cutting its consumption as in the aging baseline economy. Raising marginal income tax rates proportionally will reduce the household's labor supply, relative to the aging baseline economy, as the substitution effect of the tax rate change is larger than the income effect of the tax payment increase. The policy change will also decrease the household's saving. Relative to the 2014 benchmark economy, labor supply per capita will decrease by $10.7 \%$ in 2039 and $18.8 \%$ in the long run. Capital stock per capita will decrease by $9.0 \%$ in 2039 and $34.8 \%$ in the long run. The negative

\footnotetext{
${ }^{34}$ In Figures 11 and 14 the sign of compensating variations (in one-time wealth transfer) is reversed so that positive (negative) values show welfare gains (losses).
} 
effect of the policy change on capital stock is especially large because the policy change hits high-income households, who have the highest saving rate, most severely. Accordingly, GDP per capita will decrease by $10.0 \%$ in 2039 and $25.8 \%$ in the long run. Thus, closing the entire fiscal gap by increasing marginal income tax rates proportionally intensifies the negative effect of the aging population on the overall economy by forcing households work less and save less.

To close the fiscal gap, under this assumption, the government will have to raise marginal income tax rates proportionally by $52.1 \%$ in 2039 and $120.5 \%$ in the long run 35 This policy change will decrease the household's disposable income and consumption significantly. Relative to the 2014 benchmark economy, private consumption per capita will decrease by $5.7 \%$ in 2039 and $20.1 \%$ in the long run. Red long-dashed lines in Figure 11. show the welfare changes by age cohort. Not surprisingly, again, raising marginal income tax rates will decrease the household's average consumption significantly, thus the policy change will make most age cohorts, excluding very old households at the time of the policy change, on average worse off. What might be surprising is that, for the current and near-future households, their welfare loss is the smallest of the three policy changes (tax increases) discussed in this section, even though its effect on the overall economy is by far the worst of the three. This is because raising marginal income tax rates proportionally does not hurt low-income and retired households very much and keeps the risk-sharing effect of the current government policy.

\subsubsection{Raising the Flat Consumption Tax Rate}

Green dot-dash lines in Figure 10 show the results when the government closes the fiscal gap by raising the flat consumption tax rate instead of cutting its consumption as in the aging baseline economy. Raising the flat consumption tax rate will be close to neutral to the household's labor supply and saving. If the government increased the consumption tax rate permanently without preannouncement, the purchasing power of the current and future labor income as well as the current wealth would decrease by the same rate. When the elasticity of intra-temporal substitution between consumption and leisure is unity, as in the Cobb-Douglas utility function, the income/wealth effect of the permanent increase in the consumption tax rate is as large as its substitution effect. Thus, under this assumption, the household's labor supply and saving would not change at all. In this policy experiment, however, the flat consumption tax rate increases gradually as the demographic changes progress. This predicted increase in the consumption tax rate generates a modest substitution effect and increases the household's labor supply and saving slightly in the short run. Relative to

\footnotetext{
${ }^{35}$ This means that, the marginal tax rate of $15 \%$ in 2014 will have to increase to $22.8 \%$ in 2039 and $33.1 \%$ in the long run, and the tax rate of $35 \%$ will be $53.2 \%$ in 2039 and $77.2 \%$ in the long run.
} 
the 2014 benchmark economy, labor supply per capita will decrease by $8.0 \%$ in 2039 and $11.9 \%$ in the long run. Capital stock per capita will increase by $0.4 \%$ in 2039 and $0.1 \%$ in the long run. Accordingly, GDP per capita will decrease by $4.6 \%$ in 2039 and $7.2 \%$ in the long run. Thus, closing the fiscal gap by raising the flat consumption tax rate generates the similar macroeconomic effect to the aging baseline economy where the government cuts its consumption instead.

To close the fiscal gap, the government will have to raise the consumption tax rate by 5.8 percentage points in 2039 and 9.3 percentage points in the long run. This policy change will decrease the household's purchasing power (real disposable income) and consumption. Relative to the 2014 benchmark economy, private consumption per capita (before tax) will decrease by $3.9 \%$ in 2039 and $7.3 \%$ in the long run. Green dot-dash lines in Figure 11 show the welfare changes by age cohort. Again, raising the flat consumption tax rate will decrease the household's average consumption significantly, thus the policy change will make all age cohorts worse off. The welfare losses are between the previous two policy changes for the current and near-future households but the smallest (best) for households in the long run of the three policy changes (tax increases) discussed in this section.

\subsection{Social Security Benefits and Payroll Taxes}

This section introduces three policy changes in the Social Security program-cutting Social Security (OASI, DI, HI) benefits proportionally, raising Social Security (OASI, DI, HI) payroll taxes proportionally, and the combination of the above two policy changes - to show the effects of stylized Social Security reform plans. More precisely, the government adjusts the benefits or the tax rates or both of OASI, DI, and HI programs independently to balance the budgets of these three programs balance each year. Then, the government adjusts the flat consumption tax rate to balance the rest of the government budget each year 36 In the 2014 benchmark economy, the Social Security (OASDHI) budget is imbalanced with deficits. This is because the model abstracts from the OASI and DI trust funds and interest incomes, which would have been the government's revenue had it not been the primary deficits in the Social Security budget. In these policy experiments, when the Social Security budget is balanced, the government can reduce the consumption tax rate to balance the rest of the budget each year. Figures 12 and 13 show the macroeconomic and budgetary effects of these two policy changes, and Figure 14 shows the welfare effect of the same policy changes. Again, the first two figures include the results in the aging-population baseline economy for easier comparison.

\footnotetext{
${ }^{36}$ This paper assumes to change the consumption tax rate to balance the rest of the government budget because, as the previous section shows, the macroeconomic effect of the change in the consumption tax is modest relative to the other tax policy changes.
} 
Figure 12: The Macroeconomic and Budgetary Effects of the Aging Population (2-a) (Changes from the 2014 Benchmark Economy)
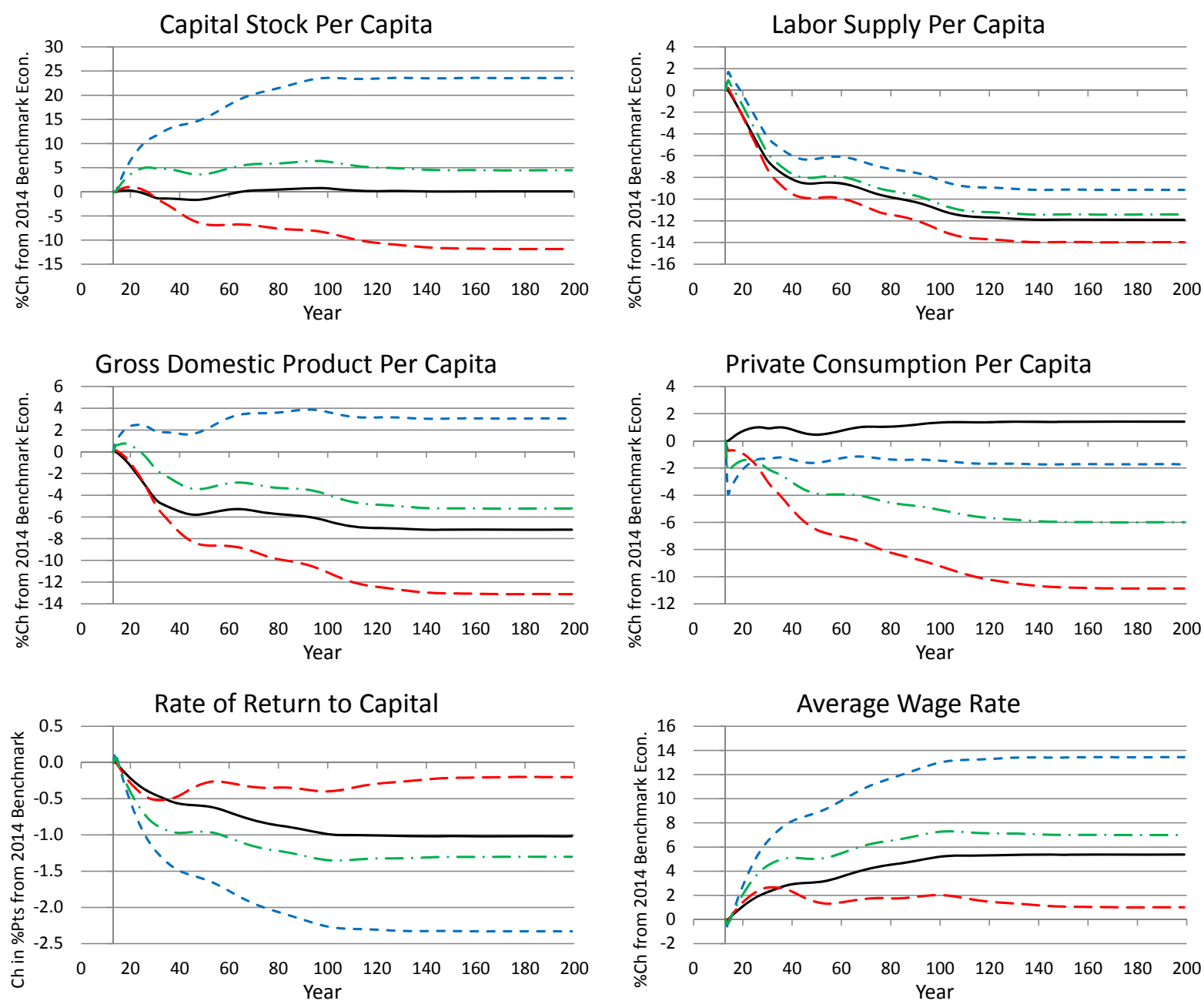

\section{SS (OASDHI) Benefits Per Capita}
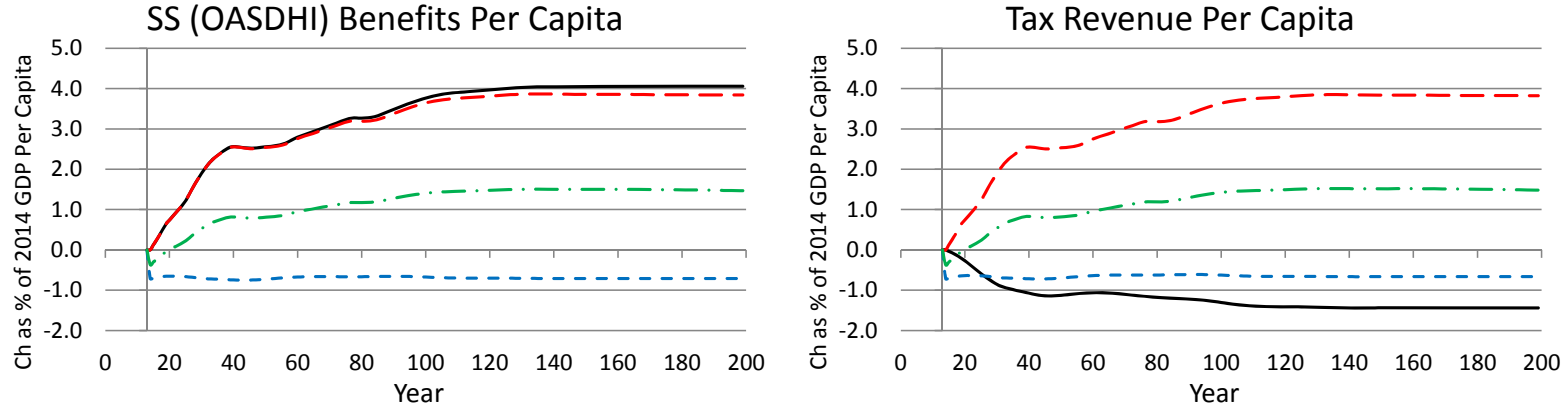

- Cutting Gov't Consumption

- - Raising SS Payroll Tax Rates

\section{- - - Cutting OASDHI Benefits \\ - - - Cutting Benefits \& Raising Tax Rates}


Figure 13: The Macroeconomic and Budgetary Effects of the Aging Population (2-b) (Changes from the 2014 Benchmark Economy)
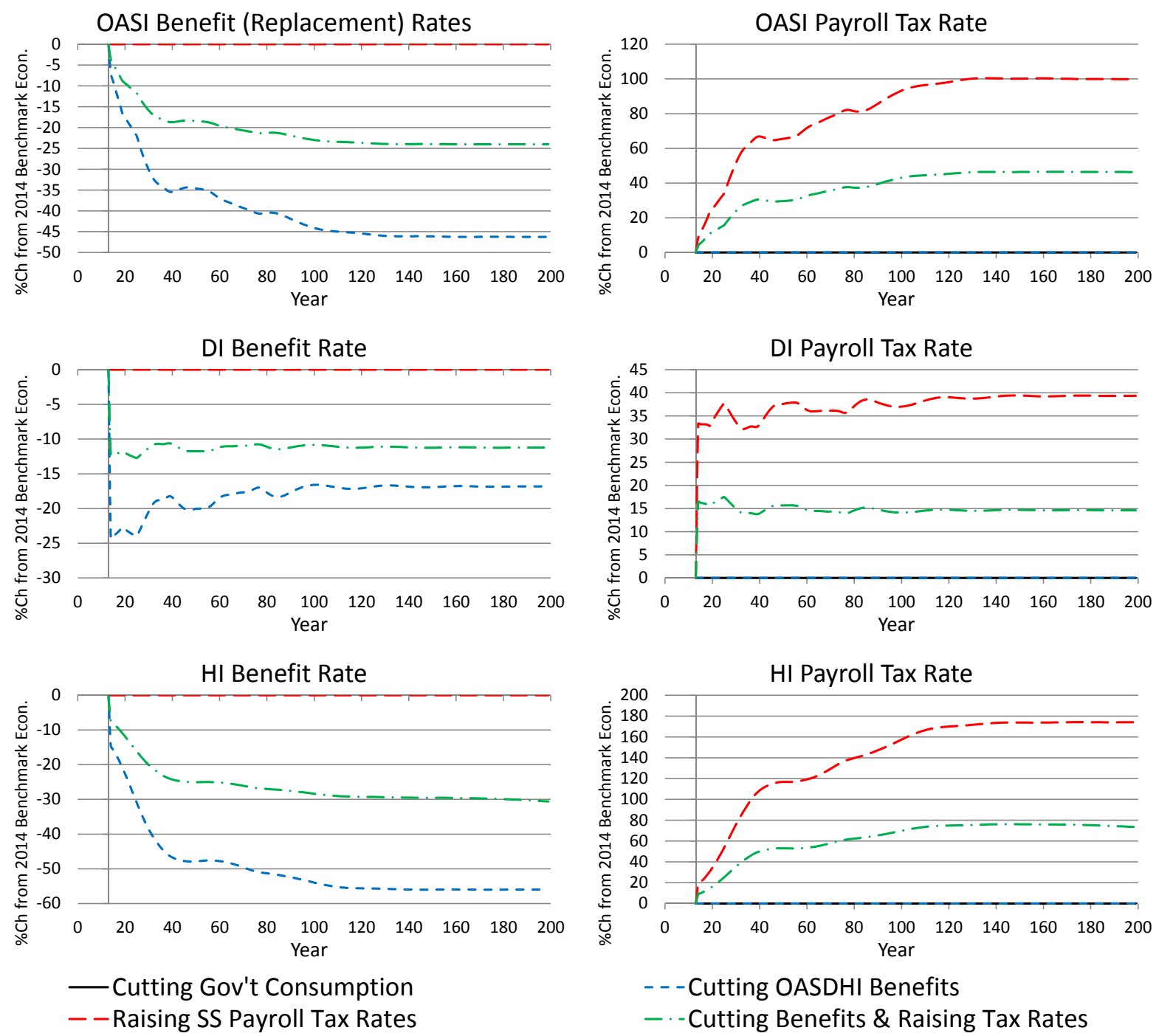

\subsubsection{Cutting Social Security Benefits Proportionally}

Blue dashed lines in Figures 12 and 13 show the macroeconomic effects when the government closes the fiscal gap by cutting Social Security (OASI, DI, HI) benefits proportionally to balance each of the three budgets and adjusting the consumption tax rate to balance the rest of the government budget. Cutting Social Security benefits will generate a very large effect on the household's life cycle saving for their retirement and a modest effect on their precautionary saving. To accumulate higher wealth before retirement, relative to the aging baseline economy, the household will work longer and increase their life cycle and precautionary savings. Relative to the 2014 benchmark economy, labor supply per capita will decrease by $5.9 \%$ in 2039 
Figure 14: The Welfare Effects of the Aging Population (2) (Changes from the Aging-Population Baseline Economy)
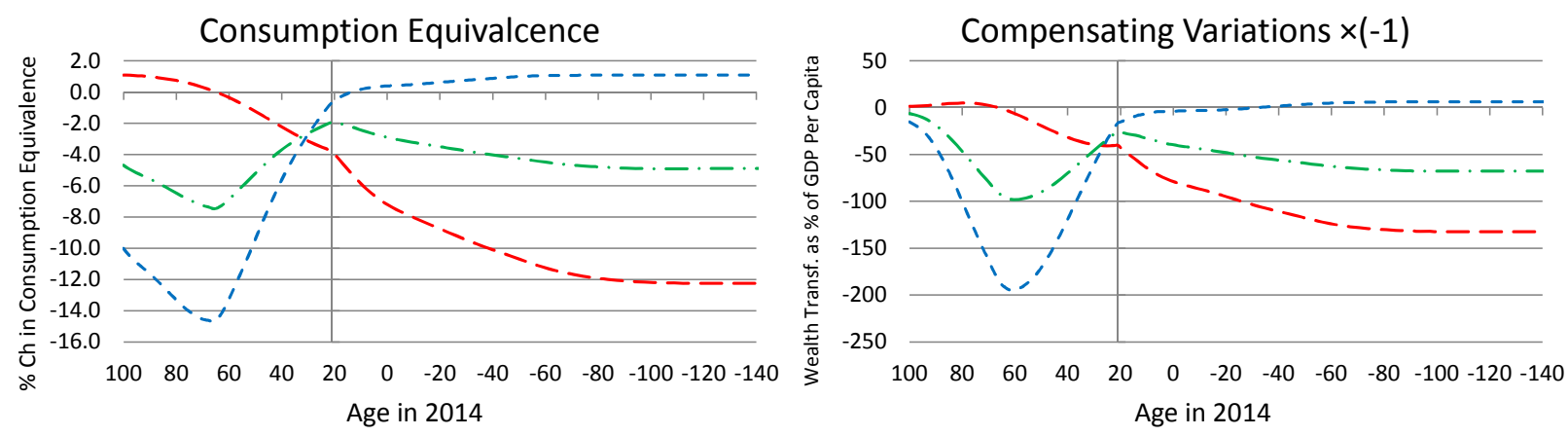

- - - Cutting OASDHI Benefits - - Raising SS Payroll Tax Rates - - - Cutting Benefits \& Raising Tax Rates

and $9.2 \%$ in the long run. Capital stock per capita will increase by $13.7 \%$ in 2039 and $23.6 \%$ in the long run. Accordingly, GDP per capita will increase by $1.7 \%$ in 2039 and $3.1 \%$ in the long run. Thus, closing the fiscal gap by cutting Social Security benefits actually increases the output and capital stock per capita in the economy despite that labor supply per capita decreases because of the demographic change.

To balance the Social Security budget, under this assumption, the government will have to cut the OASI replacement rates proportionally by $35.4 \%$ in 2039 and $46.2 \%$ in the long run, the DI benefits by $18.2 \%$ in 2039 and $16.8 \%$ in the long run, and the HI benefits by $46.3 \%$ in 2039 and $56.0 \%$ in the long run. To balance the rest of the government budget, however, the government will be able to reduce the consumption tax rate modestly by 0.5 percentage points in 2039 and 0.2 percentage points in the long run. Cutting Social Security benefits will decrease the household's disposable income and consumption significantly. Relative to the 2014 benchmark economy, private consumption per capita will decrease, on average, by $1.3 \%$ in 2039 and $1.7 \%$ in the long run. Blue dashed lines in Figure 14 show the welfare changes by age cohort under this assumption. Cutting Social Security benefits will hurt the current elderly and working-age households, especially those near the retirement age, seriously. In the consumption equivalence measure, households age 67 at the time of the policy change will be worse off, on average, by $14.7 \%$ of their (rest of the) lifetime consumption. In the compensating variations measure, households age 61 at the time of the policy change will suffer the welfare loss equivalent to one-time wealth loss of $195 \%$ of GDP per capita. Because of that, cutting Social Security benefits will be politically difficult to introduce, although this policy change will generate strong positive effects on the economy and will be least harmful for most future age cohorts of all five financing assumptions in this paper. 


\subsubsection{Raising Social Security Payroll Taxes Proportionally}

Red long-dashed lines in Figures 12 and 13 show the macroeconomic effects when the government closes the fiscal gap by increasing Social Security (OASI, DI, HI) payroll tax rates proportionally to balance each of the three budgets and adjusting the consumption tax rate to balance the rest of the government budget. Raising Social Security payroll tax rates will generate a similar effect on the household's labor supply to that of increasing marginal income tax rates. Since payroll tax rates are flat rather than progressive, however, raising these tax rates will not decrease the overall labor supply as much as increasing marginal income tax rates proportionally. As there is no change in the tax rate on capital income, raising payroll tax rates will not also discourage the household's saving by itself. Relative to the 2014 benchmark economy, labor supply per capita will decrease by $9.4 \%$ in 2039 and $14.0 \%$ in the long run. Capital stock per capita will decrease by $4.0 \%$ in 2039 and $11.8 \%$ in the long run. Accordingly, GDP per capita will decrease by $7.2 \%$ in 2039 and $13.1 \%$ in the long run. Thus, closing the fiscal gap primarily by raising Social Security payroll tax rates exacerbates the negative effect of the aging population on the overall economy, but this policy is less harmful than closing the fiscal gap solely by increasing marginal income tax rates.

To balance the Social Security budget, under this assumption, the government will have to raise the OASI payroll tax rate (below the maximum taxable earnings) by $66.7 \%$ in 2039 and $99.8 \%$ in the long run, the DI payroll tax rate by $32.7 \%$ in 2039 and $39.3 \%$ in the long run, and the HI payroll tax rate by $106.6 \%$ in 2039 and $174.1 \%$ in the long run. To balance the rest of the government budget, the government will also have to raise the consumption tax rate by 0.4 percentage points in 2039 and 1.6 percentage points in the long run. Relative to the 2014 benchmark economy, private consumption per capita will decrease, on average, by 4.8\% in 2039 and $10.9 \%$ in the long run. Red long-dashed lines in Figure 14 show the welfare changes by age cohort under this assumption. Raising Social Security payroll tax rates will hurt all age cohorts except for the elderly households at the time of the policy change. The welfare loss by age cohort is similar to that when the government increases marginal income tax rates. Therefore, most current households prefer raising Social Security payroll tax rates to other stylized policy changes discussed in this section. However, this policy change will affect the macro economy significantly and hit future households most severely among all policy changes.

\subsubsection{Cutting S.S. Benefits and raising Payroll Taxes Proportionally}

Green dot-dash lines in Figures 12 and 13 show the macroeconomic effects of the combination of the above two Social Security policy changes. This paper assumes that about $50 \%$ of Social Security deficits are financed by cutting benefits and the remaining Social Security deficits are financed by raising payroll 
taxes ${ }^{37}$ Not surprisingly, the policy effects of this policy change are about in the middle of the previous two policy changes. Relative to the 2014 benchmark economy, labor supply per capita will decrease by $7.6 \%$ in 2039 and $11.4 \%$ in the long run. Capital stock per capita will increase by $4.4 \%$ in 2039 and $4.5 \%$ in the long run. Accordingly, GDP per capita will decrease by $2.8 \%$ in 2039 and 5.2\% in the long run. In terms of total output, cutting Social Security benefits and raising payroll taxes, roughly on the 50-50 basis, will generate better results relative to cutting government consumption as in the aging baseline economy.

To balance the Social Security budget, under this assumption, the government will have to cut the OASI replacement rates by $18.7 \%$ (24.0\%) in 2039 (in the long run), cut the DI benefits by $10.6 \%$ (11.2\%), cut the HI benefits by $24.1 \%$ (30.6\%), raise the OASI payroll tax rate by $30.5 \%$ (46.3\%), raise the DI payroll tax rate by $13.8 \%(14.6 \%)$, and raise the HI payroll tax rate by $49.2 \%$ (73.4\%). Relative to the 2014 benchmark economy, private consumption per capita will decrease, on average, by $2.9 \%$ in 2039 and $6.0 \%$ in the long run. Green dot-dash lines in Figure 14 show the welfare changes by age cohort under this assumption. The combination of cutting Social Security benefits and raising payroll taxes will distribute the pains from closing the fiscal gap relatively equally between the current households and the future households. So, considering both the effects on the macro economy (efficiency) and the welfare changes by age (generational equity), this policy change would be one of the most acceptable policy changes.

\section{Concluding Remarks}

This paper incorporates historical and projected demographic changes, provided by the U.S. Social Security Administration, to a heterogeneous-agent OLG model with uninsurable wage and mortality shocks. The paper analyzes the general-equilibrium effects of the aging population on the behavior and well-being of heterogeneous households, the government's budget, and the aggregate economy over 2014-2200. The projected improvement in longevity will make working-age households work longer and save more to prepare for their retirement. However, the decreasing share of the working-age households will significantly decrease the aggregate labor supply and GDP relative to the benchmark economy without the aging population. These changes in macroeconomic variables will also decrease the government's tax revenue and increase its transfer spending. Thus, the aging population will make the current-law fiscal policy unsustainable and force the government to change its policy eventually.

This paper has two main contributions to the literature. First, this paper incorporates the SSA's popu-

\footnotetext{
${ }^{37}$ Both cutting Social Security benefits and raising payroll taxes will affect the household's behavior and thus the Social Security budget further. the government cannot change the benefit schedules and the payroll tax rates so that the contribution of each policy change to the budget will be exactly $50 \%$ of the total contribution.
} 
lation projections directly to a general-equilibrium OLG model so that the model can capture the effects of retiring the current baby-boom generation, declining mortality rates, and stable but relatively low fertility rates at the same time. Second, this paper uses a heterogeneous-agent OLG model with idiosyncratic wage shocks and mortality shocks so that the model can appropriately replicate the government's fiscal policy tools-the progressive income tax and the progressive Social Security system - and analyze the policy effects through inter-generational and intra-generational income redistribution and risk sharing. One of the difficulties to incorporate historical and projected population distributions to a heterogeneous-agent OLG model is that the current population distribution is not stationary and, thus, a stationary equilibrium cannot describe the current economy. To deal with this problem, this paper creates the 2014 benchmark economy by solving the model for an equilibrium transition path between 1975 and 2200.

This paper then introduces six stylized fiscal policy changes to finance the budgetary cost of the aging population in the future. This paper intentionally chooses simple stylized policy changes to emphasize to what extent the effect of the aging population will differ depending on how the government closes the fiscal gap. For example, we can consider increasing lump-sum taxes uniformly and raising marginal income tax rates proportionally as two polar cases of a tax increase in terms of its progressivity. Thus, these two cases roughly show the possible range of the macroeconomic and welfare effects of the aging population with a budgetary feedback. Updating the model used in this paper, we can easily analyze the effects of more complex policy changes, such as a deficit-financing policy change, a phased-in policy change, or more specifically, an increase in the full retirement age, an increase in the maximum taxable earnings for the OASDI payroll tax, a means-tested OASI benefits, and so on. In this way, the model and the procedure demonstrated in this paper will work as the platform of the future fiscal policy analyses on the aging population and help policymakers by providing both macroeconomic and distributional effects of their reform plans aimed to close the fiscal gap generated by the aging population.

\section{References}

[1] Auerbach, Alan J., and Laurence J. Kotlikoff. 1987. Dynamic Fiscal Policy. Cambridge, UK: Cambridge University Press.

[2] Attanasio, Orazio P., Sagiri Kitao, and Giovanni L. Violante. 2006. "Quantifying the Effects of the Demographic Transition in Developing Economics." The B.E. Journal of Macroeconomics, 6 (1): 1-44.

[3] Attanasio, Orazio P., Sagiri Kitao, and Giovanni L. Violante. 2007. "Global Demographic Trends and Social Security Reform.” Journal of Monetary Economics, 54: 144-198. 
[4] Board of Governors of the Federal Reserve System. 2014. "2013 Survey of Consumer Finances.” http://www.federalreserve.gov/econresdata/scf/scfindex.htm.

[5] Braun, R. Anton, Daisuke Ikeda, and Douglas H. Joines. 2009. “The Saving Rate in Japan: Why It Has Fallen and Why It Will Remain Low.” International Economic Review, 50 (1): 292-321.

[6] Chen, Kaiji, Ayşe İmrohoroğlu, and Selahattin İmrohoroğlu. 2007. "The Japanese Saving Rate Between 1960 and 2000: Productivity, Policy Changes, and Demographics.” Economic Theory, 32: 87104.

[7] Conesa, Juan C., Sagiri Kitao, and Dirk Krueger. 2009. “Taxing Capital? Not a Bad Idea after All!” American Economic Review, 99 (1): 25-48.

[8] De Nardi, Mariacristina, Selahattin İmrohoroğlu, and Thomas J. Sargent. 1999. "Projected U.S. Demographics and Social Security." Review of Economic Dynamics, 2: 575-615.

[9] Domeij, David, and Jonathan Heathcote. 2004. "On the Distributional Effects of Reducing Capital Taxes." International Economic Review, 45 (2): 523-554.

[10] Gouveia, Miguel, and Robert P. Strauss. 1994. "Effective Federal Individual Income Tax Functions: An Exploratory Empirical Analysis.” National Tax Journal, 47 (2): 317-339.

[11] Huggett, Mark. 1996. "Wealth Distribution in Life-Cycle Economies." Journal of Monetary Economics, 38 (3): 469-494.

[12] İmrohoroğlu, Ayşe, Selahattin İmrohoroğlu, and Douglas H. Joines. 1995. "A Life-Cycle Analysis of Social Security." Economic Theory, 6 (1): 83-114.

[13] Internal Revenue Service. 2015. "Form 1040 Instructions 2014." Department of the Treasury, http: //http://www.irs.gov/pub/irs-pdf/i1040gi.pdf.

[14] Kitao, Sagiri. 2014. "Sustainable Social Security: Four Options." Review of Economic Dynamics, 17: $756-79$.

[15] Kotlikoff, Laurence J., Kent Smetters, and Jan Walliser. 2007. "Mitigating America's demographic Diremma by Pre-funding Social Security ." Journal of Monetary Economics, 54: 246-66.

[16] Krueger, Dirk, and Alexander Ludwig. 2007. "On the Consequences of Demographic Change for Rates of Returns to Capital, and the Distribution of Wealth and Welfare." Journal of Monetary Economics, 54: 49-87. 
[17] Ludwig, Alexander, Thomas Schelkle, and Edgar Vogel. 2012. "Demographic Change, Human Capital and Welfare." Review of Economic Dynamics, 15: 94-107.

[18] Neuman, Patricia, Juliette Cubanski, and Anthony Damico. 2015. "Medicare Per Capita Spending By Age And Service: New Data Highlights Oldest Beneficiaries.” Health Affairs, 34, no.2 (2015):335-39 (published online January 14, 2015; 10.1377/hlthaff.2014.1371)

[19] Nishiyama, Shinichi, and Kent Smetters. 2007. "Does Social Security Privatization Produce Efficiency Gains?" Quarterly Journal of Economics, 122(4): 1677-719.

[20] Nishiyama, Shinichi, and Kent Smetters. 2014. "Analyzing Fiscal Policies in a Heterogeneous-Agent Overlapping-Generations Economy.” Kenneth L. Judd and Karl Schmedders, eds., Handbook of Computational Economics, Volume 3, Chapter 3.

[21] Ríos-Rull, José-Víctor. 2001. "Population Changes and Capital Accumulation: The Aging of the Baby Boom.” The B.E. Journal of Macroeconomics, 1 (1): 1-48.

[22] Rouwenhorst, K. Geert. 1995. "Asset Pricing Implications of Equilibrium Business cycle Models." Thomas F. Cooley, ed., Frontiers of Business Cycle Research, Chapter 10.

[23] Social Security Administration. 2014. The 2014 Annual Report of the Board of Trustees of the Federal Old-Age and Survivors Insurance and Federal Disability Insurance Trust Funds. The U.S. House of Representatives, Document 113-139.

[24] Social Security Administration. 2015. Annual Statistical Supplement to the Social Security Bulletin, 2014. Social Security Administration, Publication 13-11700.

[25] United Nations. 2008. “World Fertility Data 2008: Period Fertility Indicators.” United Nations, http: //www.un.org/esa/population/publications/WFD202008/Main.html.

[26] Vespa, Jonathan, Jamie M. Lewis, and Rose M. Kreider. 2013. "America's Families and Living Arrangements: 2012-Population Characteristics.” U.S. Census Bureau, P20-570. 